DOE/ER/14374-12

\title{
PHOTOELECTROCHEMISTRY AND PHOTOCATALYSIS IN NANOSCALE INORGANIC CHEMICAL SYSTEMS
}

\author{
Final Report
}

September 1993-August 2006

Thomas E. Mallouk

Department of Chemistry

The Pennsylvania State University

University Park, PA 16802

May 2007

PREPARED FOR THE U.S. DEPARTMENT OF ENERGY

UNDER GRANT NUMBER DE-FG02-93ER14374 


\section{TABLE OF CONTENTS}

Page

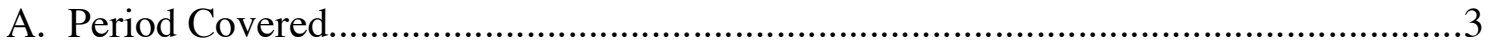

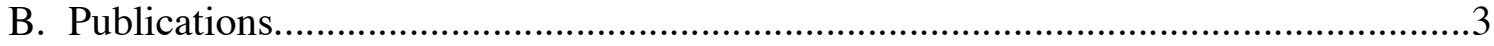

1. Manuscripts Published ......................................................................

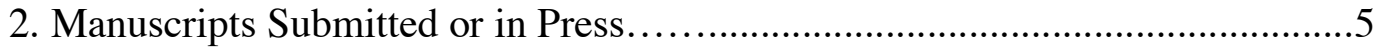

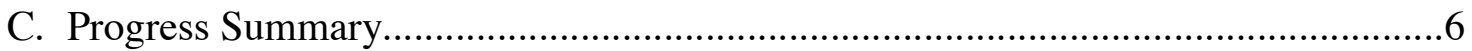

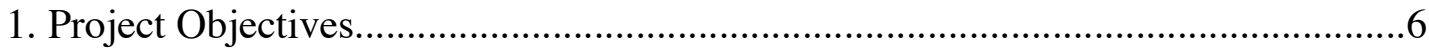

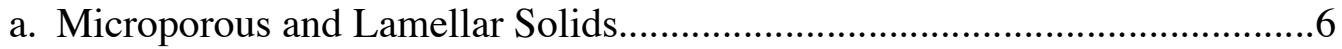

b. Light-Induced Electron and Energy Transfer............................. 8

c. Design Principles for New Photocatalysts and Photoelectrodes..............10

2. Photoinduced Reactions in Supramolecular Systems.............................10

a. Photoinduced Energy and Electron Transfer in Lamellar Heterostructures. 10

b. Edge Derivitization of Zirconium Phosphate Sheets...................................15

c. Fiber Aggregates of Ru(bpy) $)_{3}$-L-Lysine Derivatives.................... 16

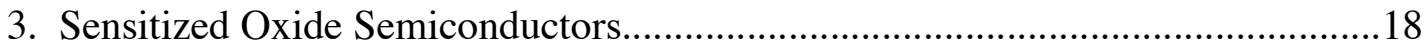

a. Photochemical Hydrogen Evolution with Nonsacrificial Electron Donors .18

b. Zeolite-Based Systems for Photochemical Hydrogen Evolution........... 22

c. Nanoscale Niobium Oxide Tubules ............................................................22

4. Colloidal Catalysts for Photochemical Oxygen Evolution.....................24

a. Colloidal Iridium Oxide and Related Composite Systems.................24

b. A High Throughput Method for Optimizing Photocatalysts.................27

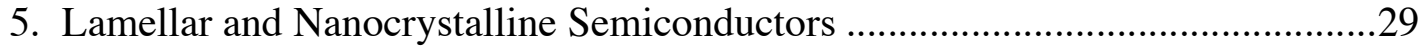

a. Oxynitride and Fluoronitride Semiconductors ..........................29

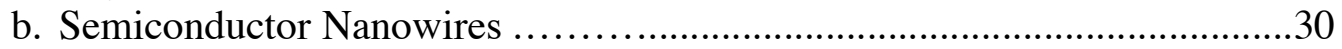

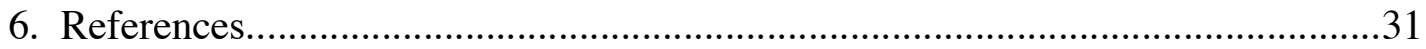


A. Period covered: September 1, 1993 - August 31, 2006

Grant period: September 1, 1993 - August 31, 2006

\section{B. Publications resulting from DOE-supported work, 1993-present:}

\section{Manuscripts published:}

1. E. S. Brigham, P. T. Snowden, Y. I. Kim, and T. E. Mallouk, "Electron and Energy Transfer as Probes of Interparticle Ion Exchange Reactions in Zeolite Y," J. Phys. Chem., 97, 8650-8655 (1993).

2. D. Rong and T. E. Mallouk, "Chemical Gating of a Molecular Bilayer Rectifier at Clay-Modified Electrodes," Inorg. Chem., 32, 1454-1459 (1993).

3. Y. I. Kim, Stephen J. Atherton, Elaine S. Brigham, and T. E. Mallouk, "Sensitized Layered Metal Oxide Semiconductor Particles for Photochemical Hydrogen Evolution from Non-Sacrificial Electron Donors," J. Phys. Chem., 97, 11802-10 (1993).

4. A. J. Bard and T. E. Mallouk, "On Septum-Based Photoelectrochemical Cells," J. Phys. Chem., 97, 7127-8 (1993).

5. E. H. Yonemoto, R. H. Schmehl, S. M. Hubig, R. L. Riley, B. L. Iverson, and T. E. Mallouk, "Electron Transfer Reactions of Ruthenium Tris(bipyridyl)-Viologen Diads: Comparison of the Distance Dependence of Electron Transfer Rates in the Normal and Marcus Inverted Regions," J. Am. Chem. Soc., 116, 4786-4795 (1994).

6. E. H. Yonemoto, Y. I. Kim, R. H. Schmehl, J. O. Wallin, B. A. Shoulders, B. R. Richardson, J. F. Haw, and T. E. Mallouk, "Photoinduced Electron Transfer Reactions in Zeolite-Based Donor-Acceptor and Donor-Donor-Acceptor Diads and Triads," J. Am. Chem. Soc., 116, 10557-10563 (1994).

7. S. W. Keller, S. A. Johnson, E. S. Brigham, E. H. Yonemoto, and T. E. Mallouk, "Photoinduced Charge Separation in Multilayer Thin Films Grown by Sequential Adsorption of Polyelectrolytes," J. Am. Chem. Soc., 117, 12879-80 (1995).

8. T. E. Mallouk, S. W. Keller, C. M. Bell, H.-G. Hong, H.-N. Kim, Y. I. Kim, D. M. Kaschak, D. L. Feldheim, P. J. Ollivier, and S. A. Johnson, "Self-Assembly of Nanostructures from Inorganic Building Blocks," Proc. Robert A. Welch Conf. on Chemical Research XXXIX Nanophase Chemistry, 1995, pp. 123-137.

9. E. S. Brigham, C. S. Weisbecker, W. E. Rudzinski, and T. E. Mallouk, "Stabilization of Intrazeolitic Cadmium Telluride Nanoclusters by Ion Exchange," Chem. Mater., $\underline{8}, 2121-7$ (1996). 
10. D. M. Kaschak and T. E. Mallouk, "Inter- and Intralayer Energy Transfer in Zirconium Phosphate-Poly(allylamine hydrochloride) Multilayers: An Efficient Photon Antenna and a Spectroscopic Ruler for Self-Assembled Thin Films," J. Am. Chem. Soc., 118, 4222-4 (1996).

11. Y. I. Kim, S. W. Keller, J. S. Krueger, G. B. Saupe, E. H. Yonemoto, and T. E. Mallouk, "Photochemical Charge Transfer And Hydrogen Evolution Mediated By Oxide Semiconductor Particles In Zeolite-Based Molecular Assemblies," J. Phys. Chem. B, 101, 2491-2500 (1997).

12. G. B. Saupe, W. Kim, R. H. Schmehl, and T. E. Mallouk, "Visible Light Photolysis of Hydrogen Iodide Using Sensitized Layered Metal Oxide Semiconductors: The Role of Surface Chemical Modification in Controlling Back Electron Transfer Reactions," J. Phys. Chem. B, 101, 2508-13 (1997).

13. C. C. Clark, J. D. Debad, E. H. Yonemoto, T. E. Mallouk, and A. J. Bard, "Effect of Oxygen on Linked Ru(bpy) $3^{2+}$-Viologen Species and Methyl Viologen - A Reinterpretation of the Electrogenerated Chemiluminescence," J. Am. Chem. Soc., 119, 10525-10532 (1997).

14. J. Kerimo, D. M. Adams, P. F. Barbara, D. M. Kaschak, and T. E. Mallouk, "NSOM Investigations of the Spectroscopy and Morphology of Self-Assembled Multilayered Thin Films," J. Phys. Chem. B, 102, 9451-9460 (1998).

15. S. W. Keller, S. A. Johnson, E. H. Yonemoto, E. S. Brigham, G. B. Saupe, and T. E. Mallouk, "Photochemically Induced Charge Separation in Electrostatically Constructed Organic-Inorganic Multilayer Composites," in Photochemistry and Radiation Chemistry: Complementary Methods for the Study of Electron Transfer, Adv. Chem. Ser. 254 (Photochemistry and Radiation Chemistry), D. G. Nocera and J. S. Wishart, Eds., pp. 359-379 (1998).

16. D. M. Kaschak, S. A. Johnson, C. C. Waraksa, J. Pogue, and T. E. Mallouk, "Artificial Photosynthesis in Lamellar Assemblies of Metal Poly(pyridyl) Complexes and Metalloporphyrins," Coord. Chem. Rev., 185-186, 403-416 (1999).

17. D. M. Kaschak, J. T. Lean, C. C. Waraksa, G. B. Saupe, H. Usami, and T. E. Mallouk, "Photoinduced Energy and Electron Transfer Reactions in Lamellar Polyanion/Polycation Thin Films: Towards an Inorganic "Leaf," J. Am. Chem. Soc., 121, 3435-45 (1999).

18. G. B. Saupe, C. C. Waraksa, H.-N. Kim, Y. J. Han, D. M. Kaschak, D. M. Skinner, and T. E. Mallouk, "Nanoscale Tubules Formed by Exfoliation of Potassium Hexaniobate," Chem. Mater., 12, 1556-1562 (2000). 
19. M. Hara, C. C. Waraksa, J. T. Lean, B. A. Lewis, and T. E. Mallouk, "Photocatalytic Water Oxidation in a Buffered Tris(2,2'-bipyridyl)ruthenium Complex-Colloidal $\mathrm{IrO}_{2}$ System," J. Phys. Chem. A, 104, 5275-5280 (2000).

20. M. Hara and T. E. Mallouk, "Photocatalytic Water Oxidation by NafionStabilized Iridium Oxide Colloids," J. Chem. Soc., Chem. Comm., 1903-4 (2000).

21. M. Hara, J. T. Lean, and T. E. Mallouk, "Photocatalytic Oxidation of Water by Silica-Supported Tris(4,4'-dialkyl-2,2'-bipyridyl)ruthenium Polymeric Sensitizers and Colloidal Iridium Oxide," Chem. Mater., 13, 4668-4675 (2001).

22. M. Suzuki, C. C. Waraksa, T. E. Mallouk, H. Nakayama, and K.Hanabusa, "Enhanced Photocatalytic Reduction of Methylviologen by Self-Assembling Ruthenium(II)Poly(pyridyl) Complexes with L-Lysine Containing Side Chains," J. Phys. Chem. B, 106, 4227-4231 (2002).

23. D. J. Pena, J. K. N. Mbindyo, A. J. Carado, T. E. Mallouk, C.D. Keating, B. Razavi, and T. S. Mayer, "Template Growth of Photoconductive Metal-CdSeMetal Nanowires," J. Phys. Chem. B, 106(30), 7458-7462 (2002).

24. M. Suzuki and T. E. Mallouk, "Photosensitized Production of Doubly Reduced Methylviologen Followed by Highly Efficient Methylviologen Radical Formation using Self-Assembling Ruthenium(II) Complexes," J. Chem. Soc., Chem. Comm., 1534-5 (2002).

25. N. D. Morris and T. E. Mallouk, "A High-Throughput Optical Screening Method for the Optimization of Colloidal Water Oxidation Catalysts", J. Am. Chem. Soc., 124, 11114-11121 (2002).

26. N. D. Morris, M. Suzuki, and T. E. Mallouk, "Kinetics of Electron Transfer and Oxygen Evolution in the Reaction of $\left[\mathrm{Ru}(\mathrm{bpy})_{3}\right]^{3+}$ with Colloidal Iridium Oxide," J. Phys. Chem.A 108, 9115-9119 (2004).

27. J. A. Schottenfeld, G. Chen, P. C. Ekerdt, and T. E. Mallouk, "Synthesis and Characterization of Layered Perovskite Oxynitride Photocatalysts from DionJacobson Oxide Precursors," J. Solid State Chem. 178, 2313-2321 (2005).

28. P. G. Hoertz and T. E. Mallouk, "Light to Chemical Energy Conversion in Lamellar Solids and Thin Films," Inorg. Chem., 44, 6828-6840 (2005).

\section{Manuscripts submitted or in press:}

1. B. A. Lewis, J. Wang, K. Jambunathan, H. Prakasam, T. S. Mayer, and T. E. Mallouk, "Laser Assisted Vapor/Liquid/Solid Growth of Photoconductive CdSe Nanocrystals in Porous Alumina Templates," submitted to Chem. Mater. 
2. D. M. Kaschak, E. S. Brigham, K. M. Smith, J. H. Pawlow, and T. E. Mallouk, "Electron and Energy Transfer Reactions in Surface-Assembled Organic/Inorganic Heterostructures," in Self-Assembly in Synthetic Chemistry, J. D. Wuest, ed., NATO Adv. Res. Workshop Ser., in press.

3. J. H. Haeni, A.M. Ellis, D. G. Schlom, S. A. Chambers, J. Schottenfeld, T. E. Mallouk, J. Robertson, W. Tian, and X. Q. Pan, "Band Structure of $\mathrm{Sr}_{2} \mathrm{TiO}_{4} / \mathrm{SrTiO}_{3}$ Heterojunctions," submitted to Appl. Phys. Lett.

\section{Progress Summary}

\section{Project Objectives}

The objective of our DOE-supported research has been to explore the use of solid state materials as organizing media for, and as active components of, artificial photosynthetic systems. In this work we strive to understand how photoinduced electron and energy transfer reactions occur in the solid state, and to elucidate design principles for using nanoscale inorganic materials in photochemical energy conversion schemes.

A major unifying theme in this project has been to move beyond the study of simple transient charge separation to integrated chemical systems that can effect permanent charge separation in the form of energy-rich chemicals. We attack this problem in several different kinds of chemical systems: micro-and meso-porous solids, which act as organizing media for electron donors and accepteors, lamellar semiconductors, which can be coupled to molecular photosensitizers and colloidal catalysts for hydrogen and oxygen evolution, and template-grown semiconductor nanowires that form arrays of miniature solar cells. In the case of lamellar systems, we have developed layer-by-layer synthetic techniques to make structurally complex assemblies for light-induced vectorial energy and electron transfer. The primary focus of our recent work has been to incorporate catalytic entities (such as noble metal and metal oxide clusters) into these assemblies to convert transiently generated holes and electrons into oxidized and reduced products. We have studied and optimized oxygen-evolving colloidal catalysts and have coupled them to supports that are compatible with layer-bylayer assembly. At the same time, we have developed and studied new sensitizers that improve the quantum yield for charge separation with lamellar oxide semiconductors. We have also made new semiconductors, analogous to wide bandgap lamellar oxides, which contain nitrogen in the lattice and absorb in the visible part of the spectrum. These new oxynitride and semiconductors can in principle eliminate the need for molecular photosensitizers, and have the potential to act as photocatalysts for visible light water splitting. Most recently, we have also begun work on semiconductor nanowires. This work exploits the idea that one can more easily grow small single crystals than larger ones, and attempts to devise ways in which arrays of small single crystals can be used for efficient conversion of solar energy to electricity or chemicals.

a. Microporous and Lamellar Solids. Two kinds of electronically insulating solids that have been used in this work to support molecular electron and energy transport chains are shown in Figure 1. These are microporous molecular sieves, represented by 
the aluminosilicate zeolites A and $\mathrm{Y}$, and lamellar microcrystalline solids, represented by $\alpha-\mathrm{Zr}\left(\mathrm{HPO}_{4}\right)_{2} \cdot \mathrm{H}_{2} \mathrm{O}$. Both of these are cation exchangers, and both have unique advantages and disadvantages for the organization of artificial photosynthetic systems.

Zeolites have crystallographically well-defined pore sizes and channel interconnections. Hence it is possible to make materials in which electroactive and/or photoactive ions are confined to specific interior or external surface sites. Molecules can be introduced to the cages by simple ion exchange reactions, or by "ship in a bottle" synthetic techniques. The polarity of the cages can also be altered by changing the framework composition, or by exchange of the extraframework cations. While these effects can be exploited to make two- and three-component electron transport chains,,$^{1-4}$ it is difficult to prepare more elaborate assemblies in zeolites because of the inherent periodic nature of the host material.,

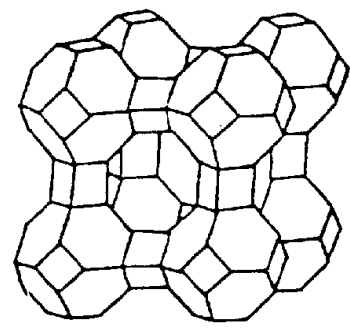

Zeolite A

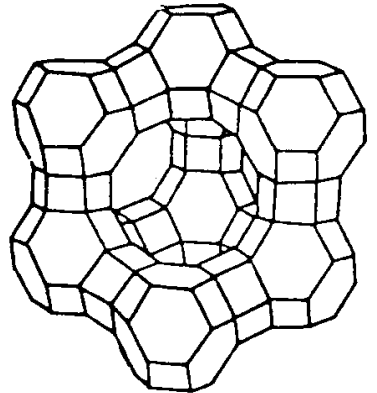

Zeolite Y

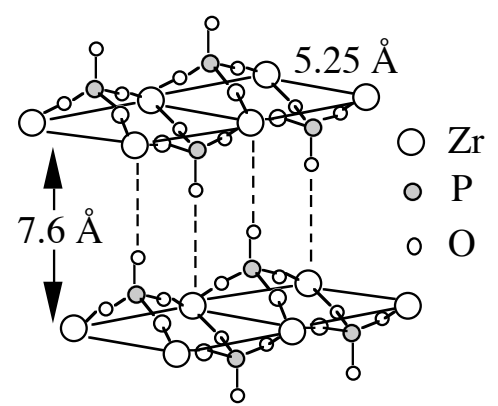

$\alpha-\mathrm{Zr}\left(\mathrm{HPO}_{4}\right)_{2} \cdot \mathrm{H}_{2} \mathrm{O}$

Figure 1. Structures of Zeolites $\mathrm{A}$ and $\mathrm{Y}$, and $\alpha-\mathrm{Zr}\left(\mathrm{HPO}_{4}\right)_{2} \cdot \mathrm{H}_{2} \mathrm{O}$.

Lamellar insulators such as $\alpha-\mathrm{Zr}\left(\mathrm{HPO}_{4}\right)_{2} \cdot \mathrm{H}_{2} \mathrm{O}$ do not provide the same kind of regular pore networks as zeolites. During ion exchange of these materials, the interlayer galleries expand to accomodate guest species, and there is generally no crystallographic ordering of ions in the $x-y$ plane. A big advantage of lamellar inorganic materials, however, is that they can be grown layer-by-layer on surfaces by sequential adsorption reactions. $^{7}$ It is therefore possible to prepare aperiodic sequences, which can accomodate, in principle, vectorial electron and energy transfer cascades containing a large number of active components.

The alkali transition metal oxides are a special case of lamellar inorganic solids. Some representative structures are shown in Figure 2. These materials are similar to $\alpha$ $\mathrm{Zr}\left(\mathrm{HPO}_{4}\right)_{2} \cdot \mathrm{H}_{2} \mathrm{O}$ in terms of their intercalation chemistry and surface assembly, but they are also semiconductors. While in most cases they absorb light only in the ultraviolet, they can be sensitized in the visible by adsorbing molecular photosensitizers, and in this case the solid acts not only as the organizing medium but also as one of the components of the electron transport chain. Again, the frameworks are typically anionic, so they can be exchanged with electroactive/photoactive cations of appropriate size. They are interesting as components of photosynthetic assemblies, and also as microscopic models for sensitized semiconductor photoelectrochemical cells. 

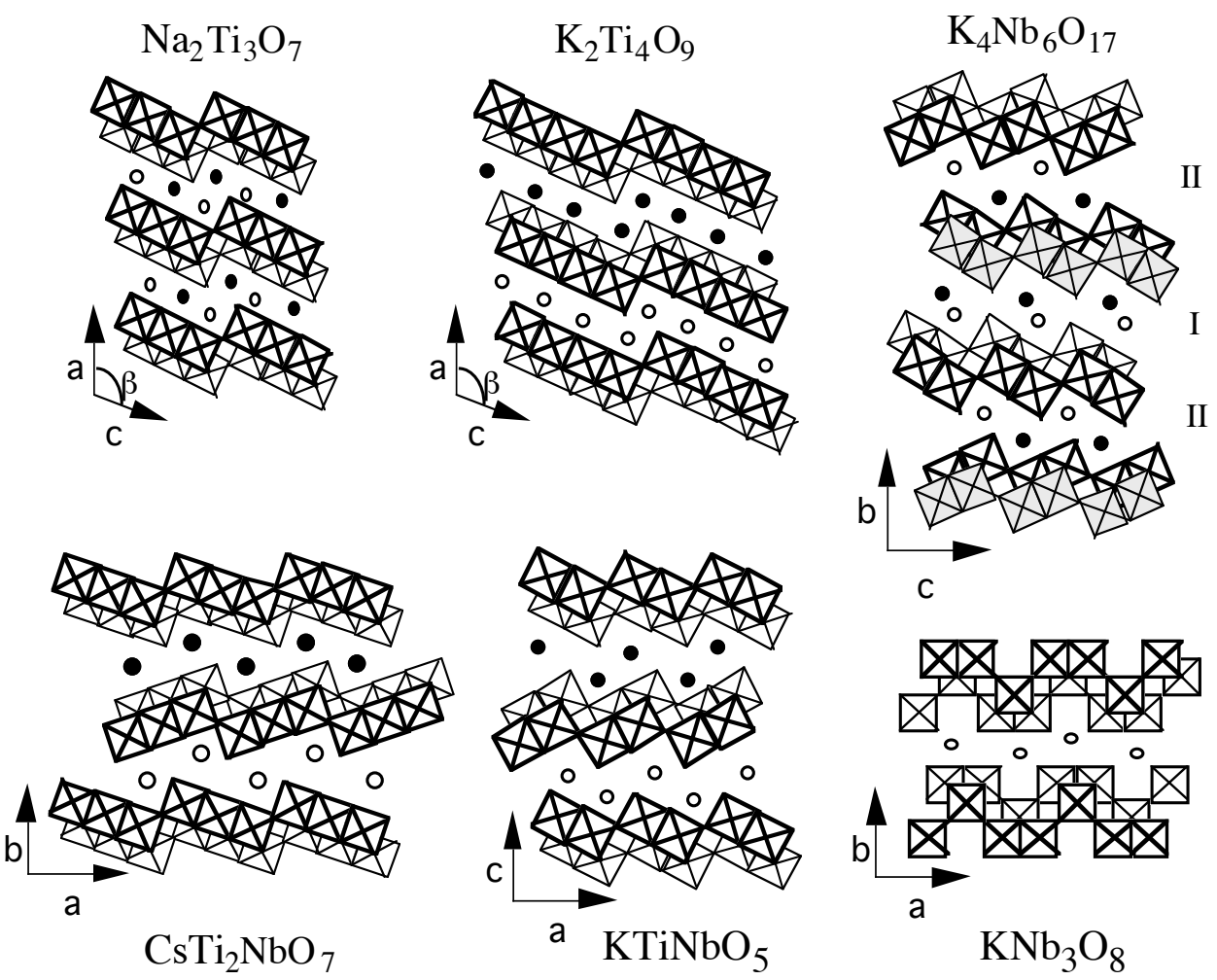

Figure 2. Idealized structures of some layered metal oxide semiconductors (LMOS).

b. Light-Induced Electron and Energy Transfer. Figure 3 shows three schematic designs that we have explored for artificial photosynthesis in hybrid solid state/molecular systems. In the first one, ion-exchange and size-exclusion effects are used to assemble a molecular photoredox triad at the zeolite/solution interface. In such a trimolecular system it is possible to have two sequential electron transfer reactions that occur quickly in the forward direction, to generate a charge-separated state in which the electron and hole are far apart.

The second scheme involves the sensitization of wide-bandgap layered metal oxide semiconductors (LMOS) with a visible light absorbing dyes. Platinum particles grown between the layers catalyze the photoreduction of protons. The most striking feature of this system is that it produces hydrogen with non-sacrificial electron donors ( $\mathrm{I}^{-}$ being the most effective one studied to date), because the layered solid sieves the oxidized donor from the interlayer space where the catalyst particles are located. The second important point with these systems is that it is possible to modulate the interfacial electron transfer rates, and in particular to slow down the energy-wasting recombination of conduction band electrons with $\mathrm{I}_{3}^{-}$, using rational surface modification techniques.

The third system is based on an approach we and others developed for growing multilayer stacks of photoactive and redox-active polymers. ${ }^{8}$ In these systems the organic polycation layers, which are typically one monolayer thick, are interleaved with polyanionic inorganic sheets. Photoredox cascades formed in this way are surface analogs of bulk intercalation compounds, except that they are aperiodic, and therefore any possible sequence can be prepared. Electronically insulating $\alpha-\mathrm{Zr}\left(\mathrm{HPO}_{4}\right)_{2} \cdot \mathrm{H}_{2} \mathrm{O}$ 
forms roughly $10 \AA$ thick spacers between the active polymer layers, which is a short enough distance to allow interlayer electron and energy transfer reactions to occur on a timescale of nanoseconds. Morphologically similar composites can be prepared from LMOS sheets, and this opens the possibility of making an internally sensitized assembly for water photolysis.
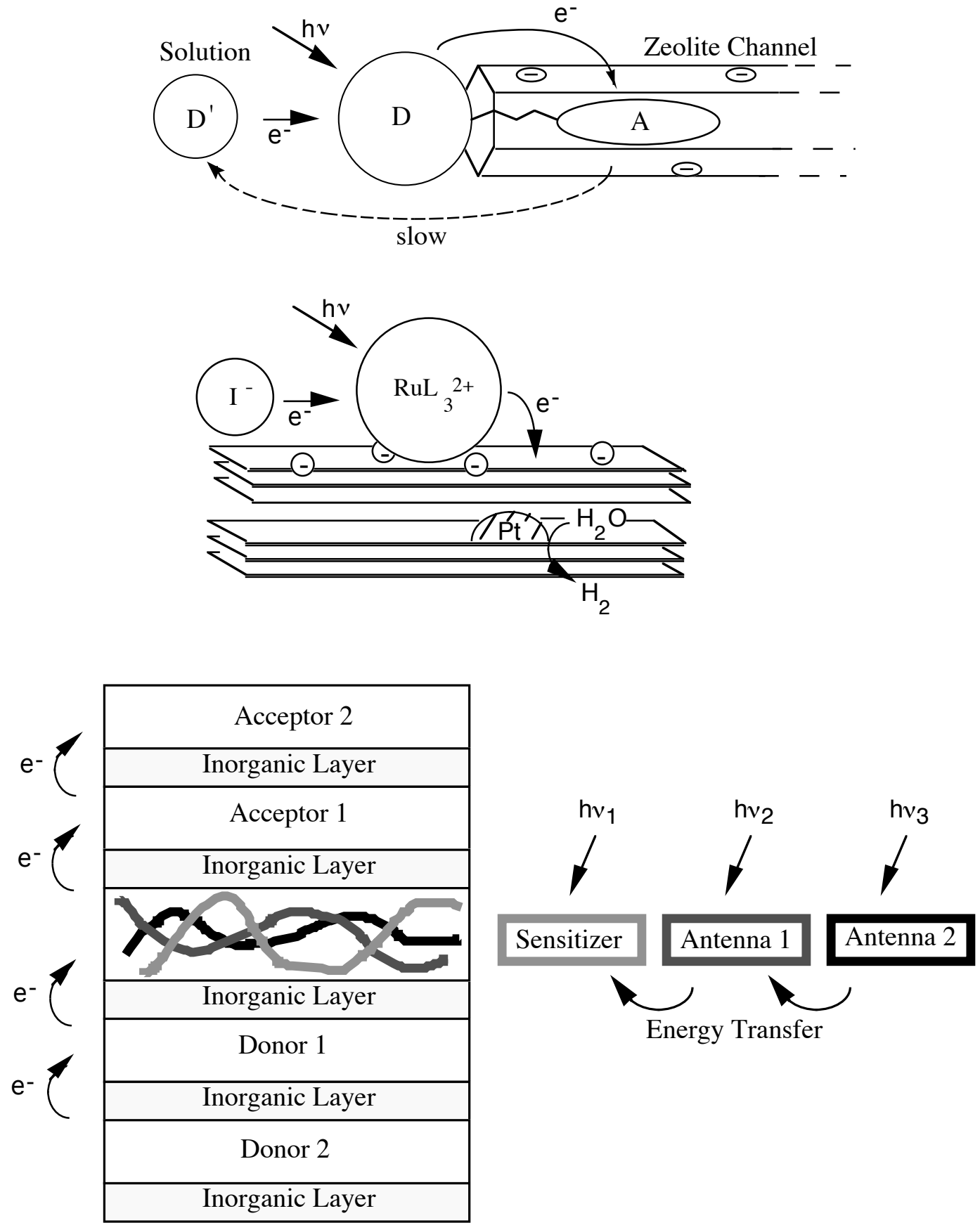

Figure 3. Three general designs for light-induced vectorial electron and energy transfer reactions in hybrid organic/solid state systems. 
c. Design Principles for New Photocatalysts and Photoelectrodes. Two new kinds of materials that we have studied are semiconductor nanowires and nitrogencontaining analogues of wide bandgap oxide semiconductors.

Arrays of semiconductor nanowires are made by a template replication technique first described by Sailor, Martin and coworkers. ${ }^{9,10}$ They found that polycrystalline CdSe nanowires grown electrochemically in porous alumina membranes on a Ni substrate show rectifying $\mathrm{i}-\mathrm{V}$ curves. We find similar effects in the dark and also observe photoconductivity. We are currently using electrochemically grown CdSe nanocrystals as seeds for the vapor phase growth of arrays of high aspect ratio single crystals. This is one example of the use of vapor-phase deposition as a route to high aspect ratio nanocrystals of semiconductors (which include $\mathrm{InP},{ }^{11} \mathrm{GaP},{ }^{12} \mathrm{n}$ - and $\mathrm{p}-\mathrm{Si},{ }^{13} \mathrm{Ge},{ }^{14} \mathrm{GaAs},{ }^{15}$ $\mathrm{In}_{\mathrm{x}} \mathrm{Ga}_{1-\mathrm{x}} \mathrm{As},{ }^{16} \mathrm{InAs},{ }^{17} \mathrm{Ag}_{2} \mathrm{Se}^{18}{ }^{18} \mathrm{TiO}_{2},{ }^{19}$ and $\mathrm{ZnO}^{20}$ ). So far these nanocrystals have been developed mainly for use in nanoscale electronics. The push has been towards smaller and smaller diameter nanowires, and little thought has been given to their photovoltaic or photoelectrochemical properties. The key to using these nanowires for solar energy conversion is to find ways to make arrays coupled to metal electrodes or catalysts for hydrogen and oxygen evolution.

Nitrogen-containing analogues of metal oxide semiconductors provide visible light absorption without the use of molecular photosensitizers. We have made oxynitride and fluoronitride analogues of both lamellar and three-dimensional alkali niobates and tantalates. The layered oxynitrides are, in principle, amenable to the kinds of topochemical reactions that we have developed for lamellar oxide semiconductors. ${ }^{21}$ Perovskite-type oxynitrides and fluoronitrides have the potential to act as photocatalysts for visible light water splitting.

\section{Photoinduced Reactions in Supramolecular Systems}

a. Photoinduced Energy and Electron Transfer in Lamellar Heterostructures. We demonstrated layer-by-layer assembly of photosystems using inorganic sheets by growing concentric "onion" structures on high surface area silica (avg. diameter $=50 \mathrm{~nm}){ }^{23}$ Utilization of high surface area particles provides good signal-to-noise ratio in flash photolysis experiments, allowing one to observe the charge separated products and determine quantum yields and kinetics (vide infra). Fumed silica particles were first derivatized with 3-aminopropyltrimethoxysilane, washed and dried, and then exposed to a suspension of exfoliated $\alpha-\operatorname{ZrP}$ sheets $(\sim 15 \times 15 \times 0.8 \mathrm{~nm})$. Following centrifugation and washing, methyl viologen-functionalized polystyrene (p$\mathrm{MV}^{2+}$ ) was deposited from aqueous solution, followed sequentially by another layer of $\alpha-$ $\mathrm{ZrP}$ sheets and a polystyrene layer functionalized with a $\mathrm{Ru}(\mathrm{II})$ poly(pyridyl) photosensitizer $\left(\mathrm{p}-\left[\mathrm{Ru}^{\mathrm{III}}(\mathrm{p}-\mathrm{bpy})(\mathrm{bpy})_{2}\right)\right]^{2+}$, abbreviated as $\mathrm{p}-\mathrm{Ru}^{2+}$, where bpy is $2,2^{\prime}-$ bipyridine and p-bpy is the 2,2'-bipyridine ligand directly attached to the polymeric backbone) (Figures 4 and 5). On planar Si surfaces, deposition of the polycationic redox layers reproducibly gave thicknesses of $\sim 9 \AA$ by ellipsometry while the $\alpha$-ZrP layers had thicknesses consistent with previous results. 


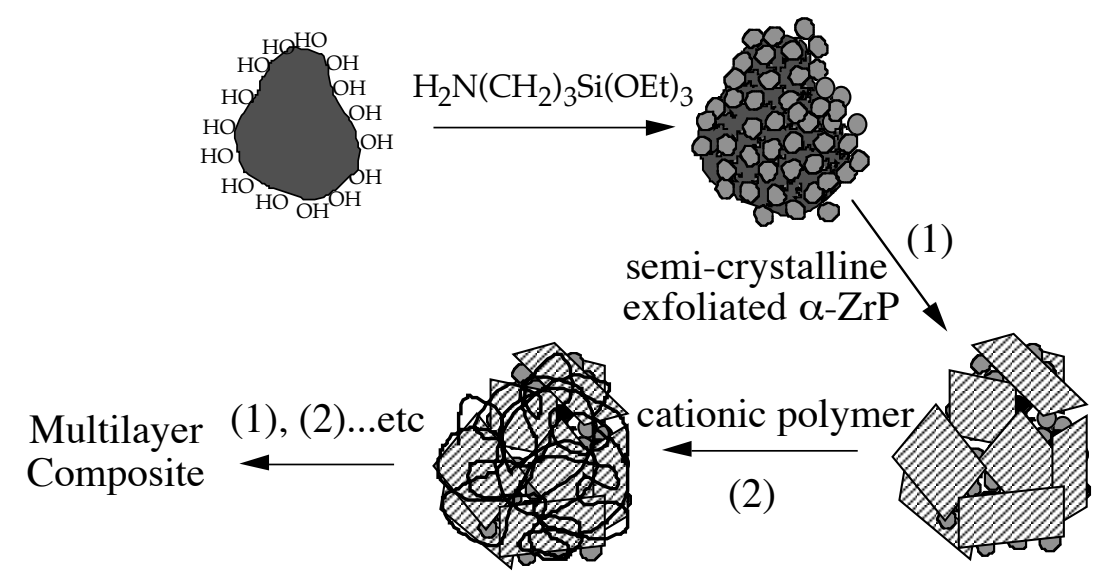

Figure 4. Schematic procedure for the preparation of the composite multilayers on high-surface area silica.
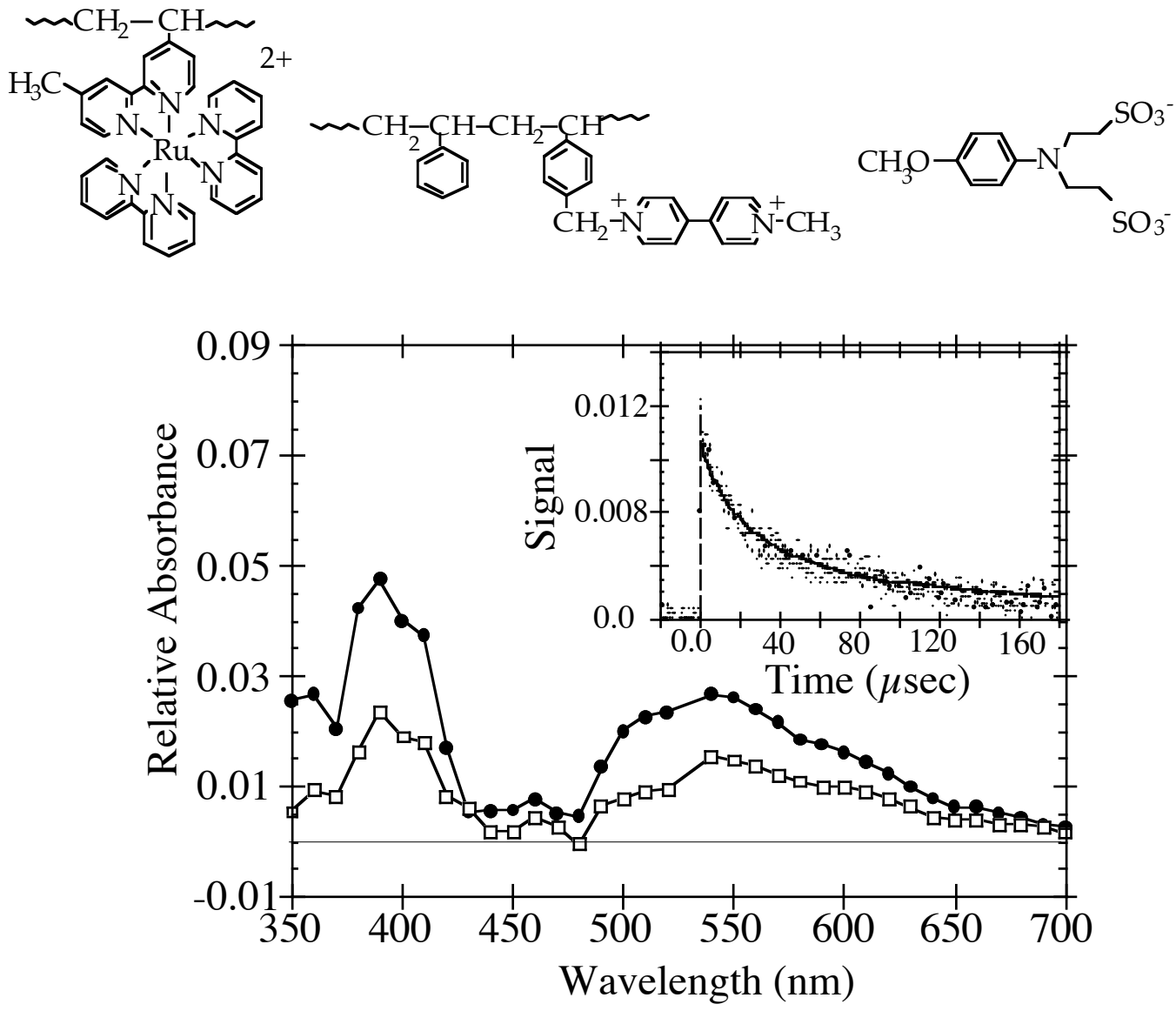

Figure 5. Top: Structures of $\mathrm{p}-\mathrm{Ru}^{2+}, \mathrm{p}-\mathrm{MV}^{2+}$, and $\mathrm{MDESA}^{2-}$. Bottom: Transient diffuse reflectance spectra for $\mathrm{p}-\mathrm{Ru}^{2+} / \mathrm{p}-\mathrm{MV}^{2+} / \mathrm{SiO}_{2}$ composite with $3.5 \mathrm{mM} \mathrm{MDESA} \mathrm{A}^{2-}$ in solution at 10 $\mu \mathrm{s}$ (filled circles) and $40 \mu \mathrm{s}$ (open squares) following $532 \mathrm{~nm}, 7 \mathrm{~ns}$ laser excitation. The inset shows the transient signal of the viologen cation radical recorded at $400 \mathrm{~nm}$, and a second-order fit to the data (solid line). 
Visible light absorption by $\mathrm{p}-\mathrm{Ru}^{2+}$ produces a metal-to-ligand charge transfer (MLCT) excited state (formally $\mathrm{p}-\left[\mathrm{Ru}^{\mathrm{III}}(\mathrm{p}-\mathrm{bpy})(\mathrm{bpy})\left(\mathrm{bpy}^{-}\right)\right]^{2+}$ ) that is a potent reductant $\left(\mathrm{E}\left(\mathrm{Ru}^{3+/ 2+*}\right) \sim-0.62 \mathrm{~V}\right.$ vs NHE$)$ capable of transferring an electron to $\mathrm{p}-\mathrm{MV}^{2+}\left(\mathrm{E}\left(\mathrm{MV}^{2+/+}\right)\right.$ $=-0.45 \mathrm{~V}$ vs NHE). Surprisingly, when $\mathrm{p}-\mathrm{MV}^{2+}$ was deposited prior to $\mathrm{p}-\mathrm{Ru}^{2+}$ (i.e. $\mathrm{p}$ $\left.\mathrm{Ru}^{2+} / \alpha-\mathrm{ZrP} / \mathrm{p}-\mathrm{MV}^{2+} / \alpha-\mathrm{ZrP} / \mathrm{SiO}_{2}\right)$, photoexcitation with $532 \mathrm{~nm}$ pulsed laser light did not produce $\mathrm{MV}^{+}$. In addition, the excited state lifetime (600 ns) was similar to that observed for $\mathrm{p}-\mathrm{Ru}^{2+} / \alpha-\mathrm{ZrP} / \mathrm{SiO}_{2}$ suggesting minimal quenching of $\mathrm{p}-\mathrm{Ru}^{2+*}$ by $\mathrm{p}-\mathrm{MV}^{2+}$. In contrast, when the reversible electron donor, methoxy- $N, N$-bis(ethylsulfonate) (MDESA ${ }^{2-}$ ), was added to the solution containing $\mathrm{p}-\mathrm{Ru}^{2+} / \alpha-\mathrm{ZrP} / \mathrm{p}-\mathrm{MV}^{2+} / \alpha-\mathrm{ZrP} / \mathrm{SiO}_{2}$, a $\mathrm{p}-\mathrm{MV}^{+} / \mathrm{MDESA}^{-}$ charge-separated state was observed with a quantum yield of $\sim 30 \%$. MDESA ${ }^{2-}$ reduces the metal center of $\mathrm{p}-\mathrm{Ru}^{2+*}$ forming a $\mathrm{Ru}^{+}$species in which one of the bipyridine ligands remains reduced:

$\operatorname{MDESA}^{2-}+$ p- $\left[\mathrm{Ru}^{\mathrm{III}}(\mathrm{p}-\mathrm{bpy})(\mathrm{bpy})\left(\mathrm{bpy}^{-}\right)\right]^{2+*} \rightarrow \operatorname{MDESA}^{--}+\mathrm{p}-\left[\mathrm{Ru}^{\mathrm{II}}(\mathrm{p}-\mathrm{bpy})(\mathrm{bpy})\left(\mathrm{bpy}^{--}\right)\right]^{+}(1)$

Experiments performed without $\mathrm{p}-\mathrm{MV}^{2+}$ indicated that excited state reduction of $\mathrm{p}-\mathrm{Ru}^{2+*}$ by MDESA $^{2-}$ occurs with a yield of $\sim 50 \%$ and involves both dynamic and static components, the latter which is made possible by ground-state adducts between oppositely-charged donor and acceptor compounds. Importantly, the $\mathrm{Ru}^{+}$species is a more powerful reductant than $\mathrm{Ru}^{2+*}$ by $\sim 0.4 \mathrm{~V}$, providing the extra driving force needed to create an interlayer charge-separated state:

$\mathrm{p}-\left[\mathrm{Ru}^{\mathrm{II}}(\mathrm{p}-\mathrm{bpy})(\mathrm{bpy})\left(\mathrm{bpy}^{-}\right)\right]^{+}+\mathrm{p}-\mathrm{MV}^{2+} \rightarrow \mathrm{p}-\left[\mathrm{Ru} \mathrm{u}^{\mathrm{II}}(\mathrm{p}-\mathrm{bpy})(\mathrm{bpy})(\mathrm{bpy})\right]^{2+}+\mathrm{p}-\mathrm{MV}^{+}$

Charge recombination followed second-order kinetics and occurred on the microsecond time-scale $\left(k_{\mathrm{obs}}=1 \times 10^{9} \mathrm{M}^{-1} \mathrm{~s}^{-1}\right)$, consistent with MDESA escaping the $\mathrm{p}^{-\mathrm{Ru}^{2+}}$ layer (escape yield $\sim 60 \%$ ). Hence, charge recombination requires diffusion of MDESAthrough both $\mathrm{p}-\mathrm{Ru}^{2+}$ and anionic $\alpha-\mathrm{ZrP}$ layers. Interestingly, when the order of polymer deposition was reversed, i.e. $\mathrm{p}-\mathrm{MV}^{2+} / \alpha-\mathrm{ZrP} / \mathrm{p}-\mathrm{Ru}^{2+} / \alpha-\mathrm{ZrP} / \mathrm{SiO}_{2}, \mathrm{p}-\mathrm{Ru}^{2+*}$ is no longer quenched by $\mathrm{MDESA}^{2-}$ and charge-separation was no longer observed with or without the electron donor. Apparently, diffusion of $\mathrm{MDESA}^{2-}$ to the buried $\mathrm{p}-\mathrm{Ru}^{2+}$ layer is severely impeded in this composite such that $\mathrm{MDESA}^{2-} / \mathrm{Ru}^{2+}$ ground-state adducts no longer form and diffusional quenching between $\mathrm{MDESA}^{2-}$ and $\mathrm{p}-\mathrm{Ru}^{2+*}$ no longer occurs. In addition, when the $\alpha-\mathrm{ZrP}$ sheets were replaced with organic poly(styrenesulfonate) (PSS), donor quenching was no longer observed presumably because $\mathrm{p}-\mathrm{Ru}^{2+}$ is intertwined with anionic PSS, preventing approach of $\mathrm{MDESA}^{2-}$. In the absence of the silica support, i.e. when $\mathrm{p}-\mathrm{Ru}^{2+}, \mathrm{p}-\mathrm{MV}^{2+}$, and $\mathrm{MDESA}^{2-}$ were dissolved together in solution, reaction 1 was observed while reaction 2 was not, presumably due to repulsion between the polycationic redox polymers.

The successful demonstration of photoinduced charge separation in this "onion" system suggested the possibility of making a more complex artificial photosynthetic system by LBL techniques. In this multilayer thin film system, light absorption was coupled to electron transfer/charge-separation by a series of energy transfers through an antenna system containing three dye molecules (Figure 6). ${ }^{24}$ The dyes that were chosen, coumarin, fluorescein, and a tetrasubstituted Pd(II) tetraphenylporphyrin (PdTPP), have large molar extinction coefficients and absorb visible light at progressively longer 

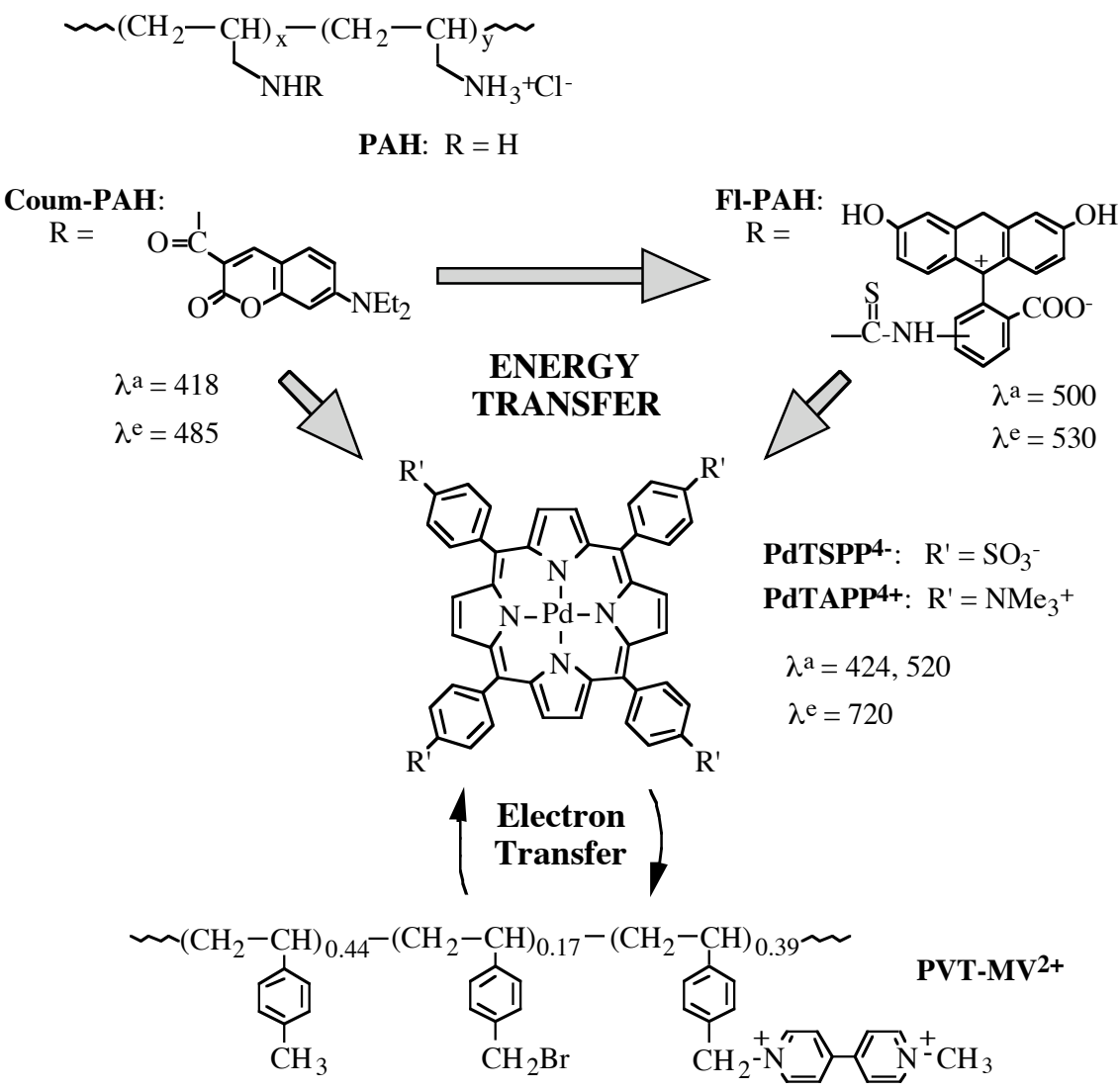

Figure 6. Molecular structures, energy and electron transfer pathways (indicated by arrows) for the energy "antenna" polymers, Coum-PAH and Fl-PAH; the photosensitizers, PdTAPP $4+$ and PdTSPP $^{4-}$; and the electron acceptor polymer, PVT-MV ${ }^{2+}$.

wavelengths. In order for Förster (i.e. singlet-singlet) energy transfer to be efficient, good spectral overlap must exist between the donor emission spectra and the acceptor absorbance spectra. Accordingly, the coumarin dye absorbs light in the blue region of the visible spectrum $\left(\lambda_{\mathrm{abs,max}}=412 \mathrm{~nm}, \lambda_{\mathrm{em}}=485 \mathrm{~nm}\right)$ and can donate its excited state energy to the fluorescein dye $\left(\lambda_{\mathrm{abs}, \max }=500 \mathrm{~nm}, \lambda_{\mathrm{em}}=530\right)$, which in turn, can transfer its excited state energy to the Pd(II) tetraphenylporphyrin $\left(\lambda_{\text {abs,max }}=520 \mathrm{~nm}, \lambda_{\mathrm{em}}=720 \mathrm{~nm}\right)$. It is also possible for the coumarin dye to transfer energy directly to the porphyrin dye as the coumarin emission and porphyrin Q-band absorbance slightly overlap Importantly, porphyrin excited states are formed by either direct excitation or indirectly by excitation of the coumarin or fluorescein dyes. Furthermore, the presence of a Pd atom in the porphyrin fluorophore ensures nearly quantitative intersystem crossing to a long-lived triplet excited state, allowing ample time for interlayer electron transfer to occur.

Two kinds of multilayer thin films assemblies were prepared through alternate anion/cation adsorption steps. For interlayer energy transfer, coumarin-functionalized 

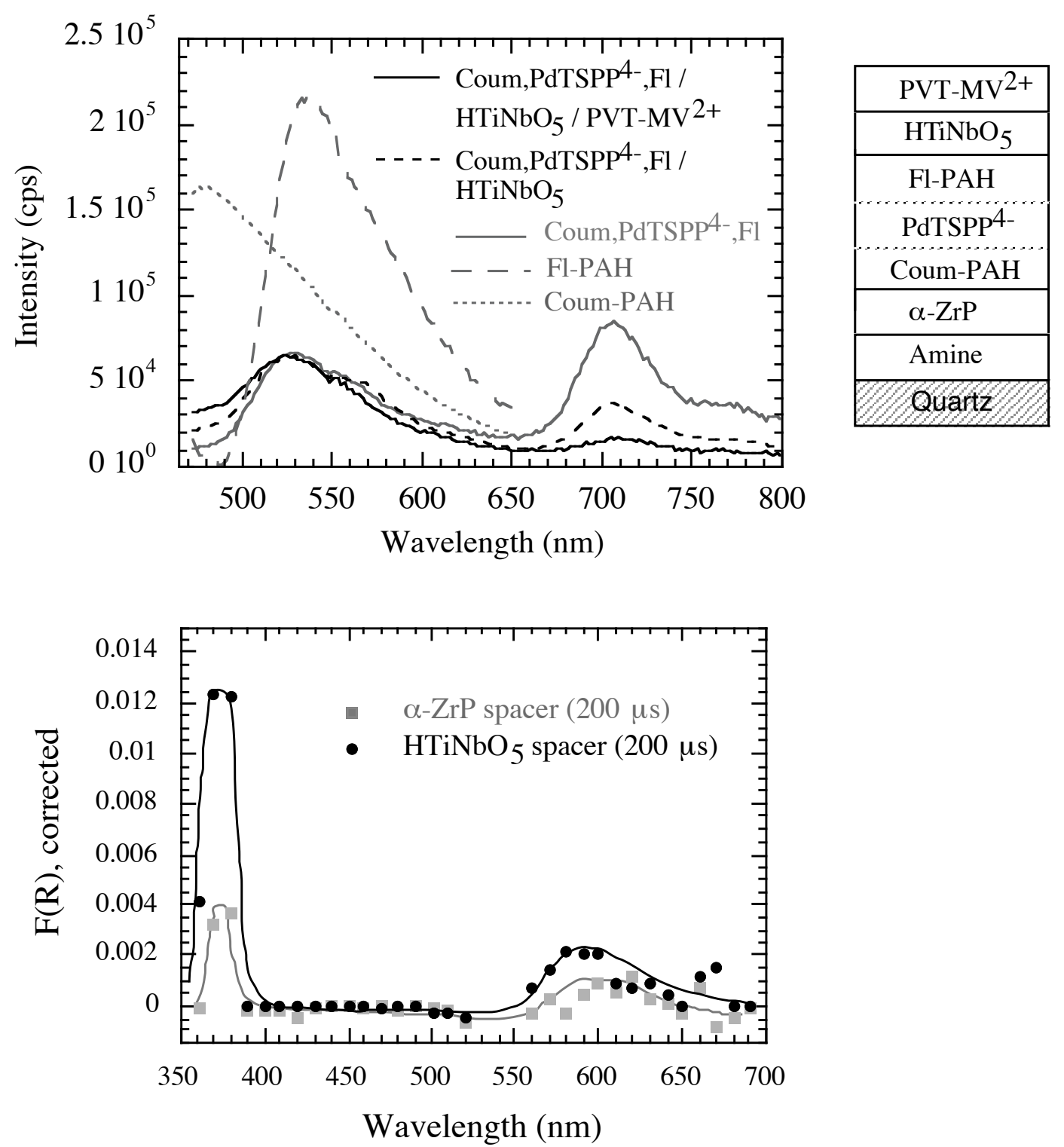

Figure 7. Top: Emission $\left(\lambda_{\mathrm{ex}}=450 \mathrm{~nm}\right)$ spectra of an energy/electron transfer assembly with HTiNbO5 spacer separating the porphyrin and viologen layers. Dotted lines in the idealized picture at the right indicate a mixed Coum-PAH, PdTSPP4-, Fl-PAH polyelectrolyte layer. Reference spectra from individual chromophore layers (Coum-PAH, PdTSPP4-, Fl-PAH) and from the triad without PVT-MV ${ }^{2+}$ are also shown. Bottom: Transient diffuse reflectance spectra taken $200 \mu$ s after $532 \mathrm{~nm}$ excitation, for silica/amine/ $\alpha-\mathrm{ZrP} / \mathrm{PVT}-\mathrm{MV}^{2+} / \alpha-\mathrm{ZrP} / \mathrm{PAH} / \mathrm{PdTSPP} 4-$ (lower gray spectrum), and silica/amine/ $\alpha-\mathrm{ZrP} / \mathrm{PVT}-\mathrm{MV}^{2}{ }^{+} / \mathrm{HTiNbO}_{5} / \mathrm{PAH} / \mathrm{PdTSPP}^{4-}$ (upper black spectrum) samples.

poly(allyl)amine hydrochloride (Coum-PAH), fluorescein-functionalized PAH (Fl-PAH), and $\mathrm{Pd}(\mathrm{II})$ tetrakis(4- $N, N, N$-trimethylanilinium)porphyrin (i.e. $\mathrm{PdTPP}^{4+}$ ) were deposited sequentially using anionic $\alpha$-ZrP layers as spacers. For intralayer energy transfer, all three polycationic dyes were adsorbed simultaneously onto anionic $\alpha-\mathrm{ZrP}$. Absorption and emission spectra of both multilayer assemblies were obtained and compared with that for individual dye layers. The emission spectra (excitation with $450 \mathrm{~nm}$ ) showed almost complete quenching for the coumarin dye, significant quenching of the fluorescein dye, 
and enhanced emission from the porphyrin. Based on the emission data, the energy transfer efficiency of the interlayer assembly was calculated to be 0.65 while that for the intralayer assembly was 0.82. The lower efficiency of the interlayer assembly was attributed to the Förster distances of the various donor-acceptor combinations being close to the $\alpha$-ZrP/dye-PAH bilayer thickness $(\sim 22 \AA)$. In contrast, the average donoracceptor distances in the intralayer assembly were significantly smaller, allowing for relatively facile energy transfer.

Since the intralayer assembly gave superior results, it was coupled to an electron acceptor layer, methylviologen-functionalized poly(vinyltoluene) ( $\mathrm{MV}^{2+}$-PVT, Figure 7). In order to provide a larger driving force for electron transfer from the porphyrin excited state to $\mathrm{MV}^{2+}$, $\mathrm{PdTPP}^{4+}$ was replaced with a tetraanionic porphyrin $\left(\mathrm{PdTPP}^{4-}\right)$, which is a more powerful triplet excited state reductant by $\sim 0.3 \mathrm{~V}$. Efficient quenching of the porphyrin phosphorescence was observed upon adding $\mathrm{MV}^{2+}$-PVT to the system, the degree of which depended on the anionic "glue" used for its fastening. Using $\mathrm{HTiNbO}_{5}$ sheets, the phosphorescence was quenched by $76 \%$, while that for $\alpha-\mathrm{ZrP}$ was $58 \%$. This corresponds to a combined energy/electron transfer quantum yield of 0.61 and 0.47 , respectively. Importantly, spectra from diffuse reflectance flash photolysis experiments for similar systems constructed on high surface area silica showed that $\mathrm{MV}^{+}$is present on the microsecond timescale and that it is produced in greater yield when the $\mathrm{HTiNbO}_{5}$ spacer is used. These results suggested that semiconducting $\mathrm{HTiNbO}_{5}$ sheets mediate the electron transfer between ${ }^{3} \mathrm{PdTPP}^{4-*}$ and $\mathrm{MV}^{2+}$, while $\alpha-\mathrm{ZrP}$, an insulator, does not. Indeed, when $\mathrm{HTiNbO}_{5}$ is layered on top of the intralayer assembly in the absence of $\mathrm{MV}^{2+}$-PVT, significant quenching of ${ }^{3} \mathrm{PdTPP}^{4-*}$ phosphorescence is observed, suggesting that electron transfer between ${ }^{3} \mathrm{PdTPP}^{4-*}$ and $\mathrm{HTiNbO}_{5}$ is occurring.

c. Edge Derivitization of Zirconium Phosphate Sheets. The base hydrolysis of $\alpha-\mathrm{ZrP}$, reaction (3), is an important side reaction that occurs in competition with exfoliation, reaction (4). Without proper precautions, the hydrolysis reaction can

$$
\begin{gathered}
\mathrm{Zr}\left(\mathrm{HPO}_{4}\right)_{2} \cdot \mathrm{H}_{2} \mathrm{O}+\mathrm{n} \mathrm{H} \mathrm{H}_{2} \mathrm{O}+2 \mathrm{x} \mathrm{OH}^{-}=\mathrm{Zr}\left(\mathrm{HPO}_{4}\right)_{2-\mathrm{x}}(\mathrm{OH})_{2 \mathrm{x}}+(1+\mathrm{n}) \mathrm{H}_{2} \mathrm{O}+\mathrm{x} \mathrm{HPO}{ }^{2-} \\
\mathrm{Zr}\left(\mathrm{HPO}_{4}\right)_{2} \cdot \mathrm{H}_{2} \mathrm{O}+\mathrm{x} \mathrm{OH} \mathrm{OH}^{-}=\left[\mathrm{Zr}\left(\mathrm{HPO}_{4}\right)_{2-\mathrm{x}}\left(\mathrm{PO}_{4}\right)_{\mathrm{x}}\right]^{\mathrm{x}-}+\mathrm{x} \mathrm{H}_{2} \mathrm{O}
\end{gathered}
$$

cause substantial corrosion of the sheets. The ultimate product of base hydrolysis, hydrous zirconia, interferes with the layer adsorption process, resulting in incomplete surface coverage. AFM and TEM images of partially hydrolyzed sheets show that reaction (1) occurs from the edges inward. ${ }^{25}$ The edges are more reactive than the basal plane surfaces, presumably because they contain phosphate groups that are bound to $\mathrm{Zr}$ atoms through two (or fewer) oxygen atoms. In contrast, the basal plane phosphates bind to $\mathrm{Zr}$ through three oxygen atoms. ${ }^{26}$

We found that a phosphonate-phosphate exchange reaction can be used to derivatize the edges of the sheet, and effectively stop the corrosion reaction. This result is important in terms of our ability to make well organized photochemical assemblies. The same reaction can also be used to place dye molecules exclusively at the edges of the sheets, either in a self-assembled monolayer or in a colloidal suspension. Figure 8 shows a fluorescence microscope image of a partial monolayer of $\alpha$-ZrP on glass, which was exposed to an aqueous RhB-P solution and then rinsed with water to remove excess dye. 


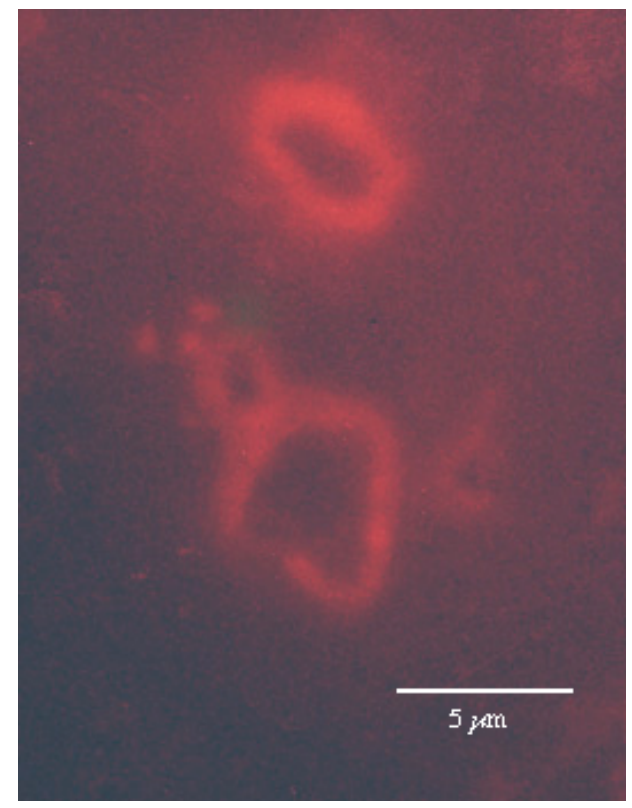

The particles show the characteristic red luminescence of $\mathrm{RhB}$, and the loop patterns are consistent with selective edge binding. Control experiments with $\mathrm{RhB}$ derivatives that contain no phosphonate group do not show edge luminescence.

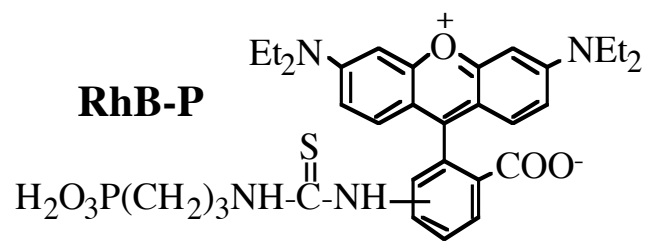

Figure 8. Fluorescence microscope image of $\alpha-\mathrm{ZrP}$ sheets derivatized at the edges with $\mathrm{RhB}-\mathrm{P}$, on a borosilicate glass cover slip.

b. Fiber Aggregates of Ru(bpy $)_{3}$-L-Lysine Derivatives. In our studies of photosensitized layered metal oxide semiconductors (see below), we found that back electron transfer between the semconductor sheets and solution-phase $\mathrm{I}_{3}{ }^{-}$in the $\mathrm{HI}$ photolysis system $\mathrm{Ru}(\mathrm{bpy})_{3}-\mathrm{P}^{2+} / \mathrm{K}_{4-\mathrm{x}} \mathrm{H}_{\mathrm{x}} \mathrm{Nb}_{6} \mathrm{O}_{17}(\mathrm{Pt})$ was inhibited by adsorbing a phosphonate SAM or polyelectrolyte layer onto the sensitizer. We attempted to append such a blocking layer covalently to the sensitizer using molecules Ru1 and Ru2,

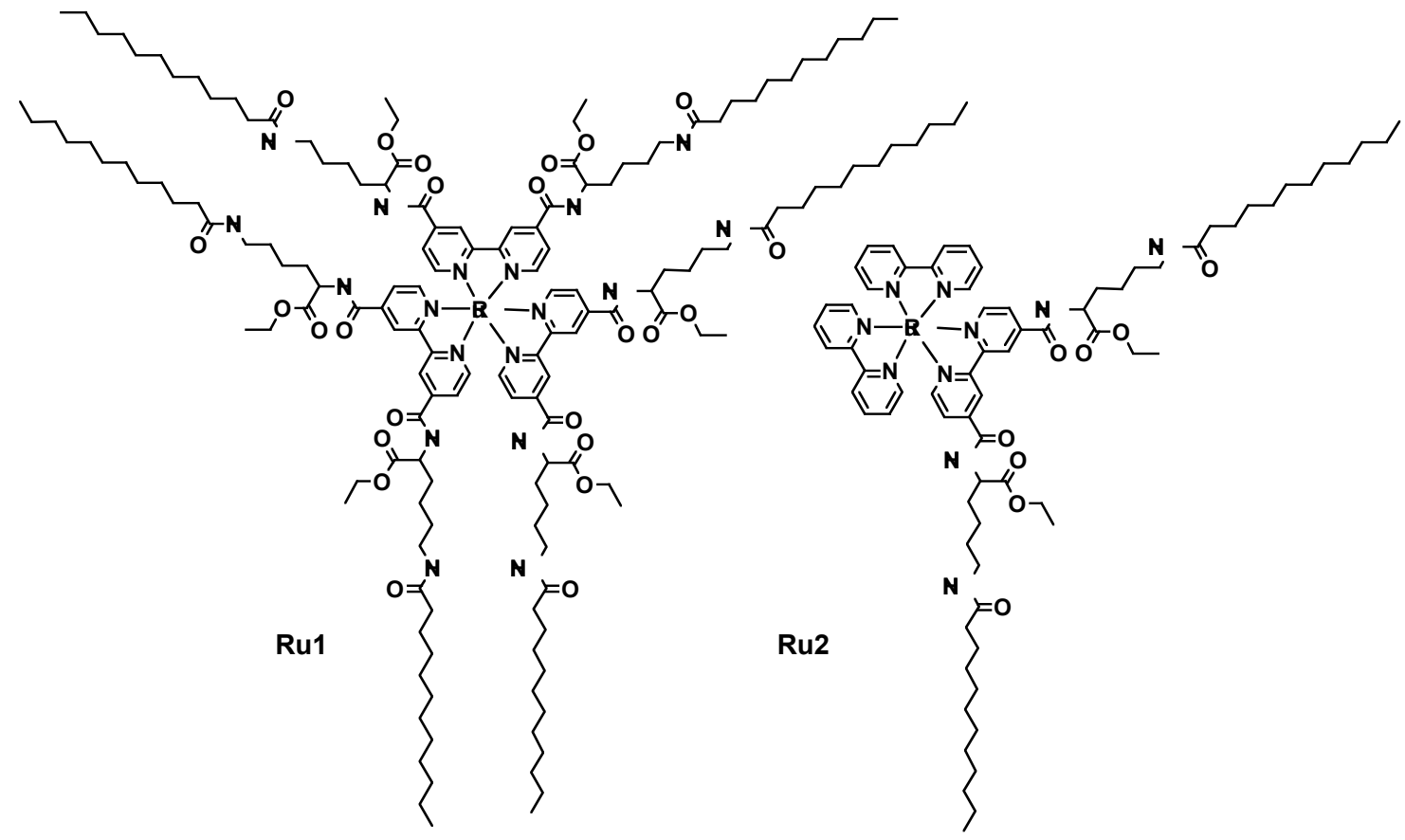

which contain aliphatic side chains linked by L-lysine groups. These amphiphilic molecules were not good sensitizers for layered oxide semiconductors because the amide groups did not couple them to the sheets, but instead caused them to form hydrogen- 
bonded networks in solution. We observed that these molecules assemble into fibrous aggregates in organic solvents, giving clear solutions at low concentration and viscous gels at higher concentration.

In the presence of $\mathrm{MV}^{2+}$ and the sacrificial electron donor triethanolamine (TEOA), Ru1 and Ru2 fibers in the fluid phase were more efficient photosensitizers than $\mathrm{Ru}(\mathrm{bpy})_{3}{ }^{2+}$, which did not aggregate under the same conditions. A detailed kinetic analysis (combining results from steady state and nanosecond transient photolysis) of this system showed that the increased rate of reduced viologen formation arises from an increased charge separation lifetime and an increased rate of reduction of $\mathrm{Ru}$ (III) to $\mathrm{Ru}$ (II) by triethanolamine. ${ }^{27}$ At low concentrations of $\mathrm{MV}^{2+}$, we were surprised to find a progressive series of photoreductions, from $\mathrm{MV}^{2+}$ to $\mathrm{MV}^{+}$to $\mathrm{MV}^{0} .^{28}$ The second reaction does not occur with $\mathrm{Ru}(\mathrm{bpy})_{3}{ }^{2+}$, and to our knowledge has not been observed before in this kind of photosystem. Again, a detailed kinetic analysis revealed that the second reduction involves a pre-equilibrium between the reduced form of the sensitizer $\left(\mathbf{R u} \mathbf{1}_{\text {red }}\right.$ or $\mathbf{R u} 2_{\text {red }}$ ) and $\mathrm{MV}^{*+}$, according to reaction (5). The oxidized sensitizer is then photoreduced (reaction (6)), giving the observed integrated rate law (7), in which $\mathrm{C}_{0}$ is the concentration of $\mathrm{MV}^{*+}$

$$
\begin{gathered}
\mathbf{R u 1}_{\text {red }}+\mathrm{MV}^{++} \stackrel{\mathrm{K}_{\mathrm{eq}}}{\rightarrow} \mathbf{R u 1}+\mathrm{MV}^{0} \\
\mathbf{R u 1}+\mathrm{TEOA}+\mathrm{h} v \stackrel{\mathrm{k}}{\rightarrow} \mathbf{R u 1}_{\text {red }} \\
\mathrm{C}_{0}\left(\ln \left[\mathrm{MV}^{*+}\right]\right)-\left[\mathrm{MV}^{++}\right]=-\mathrm{kK}_{\mathrm{eq}}\left[\mathbf{R u} \mathbf{1}_{\text {red }}\right] \mathrm{t}+\mathrm{C}_{0}\left(\ln \mathrm{C}_{0}\right)-\mathrm{C}_{0}
\end{gathered}
$$

formed in the first rapid phase of the reaction by photoreduction of $\mathrm{MV}^{2+}$. Figure 9 summarizes the electron transfer reactions of self-assembled fibers of these sensitizers.

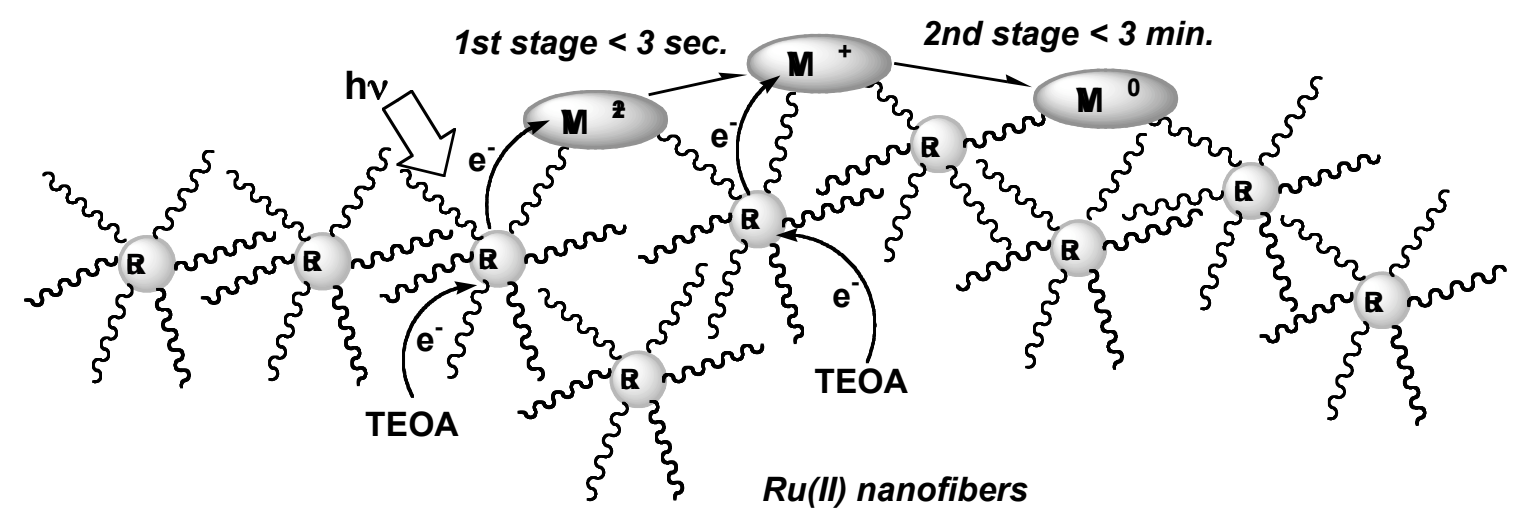

Figure 9. Illustration of the two reaction stages of methylviologen photoreduction by Ru1 and Ru2 fibers. In both stages, donor quenching generates the reduced sensitizer. Reduction of $\mathrm{MV}^{2+}$ to $\mathrm{MV}^{*+}$ occurs rapidly with a quantum yield of 0.5 . The second stage of the reaction, photoreduction of $\mathrm{MV}^{++}$to $\mathrm{MV}^{0}$, involves equilibrium (5) and occurs about two orders of magnitude more slowly. 


\section{Sensitized Oxide Semiconductors}

a. Photochemical Hydrogen Evolution with Nonsacrificial Electron Donors. Many artificial photosynthetic systems have been contructed with the purpose of transiently separating charge, or generating products from sacrificial reagents. Structural control is really most needed when non-sacrificial reagents are used because of the possibility of recombination reactions. Catalysts for generating chemical products should be spatially compartmentalized and connected by an electron relay system that disfavors charge recombination. The recombination reaction is necessarily thermodynamically downhill and favorable since free energy is stored in the charge-separated state. Compartmentalization of redox reactions is conveniently achieved in photoelectrochemical cells by carrying out oxidation and reduction reactions at spatially well-separated electrodes. However, in photochemical systems, oxidation and reduction products are typically made at the same particle. Therefore, preventing their recombination requires sieving at the molecular level.

In the first example of such a non-sacrificial artificial photosynthetic system, layered metal oxide semiconductor (LMOS) sheets of $\mathrm{K}_{4-\mathrm{x}} \mathrm{H}_{\mathrm{x}} \mathrm{Nb}_{6} \mathrm{O}_{17} \cdot n \mathrm{H}_{2} \mathrm{O}(\mathrm{x} \sim 2.5)$ were sensitized with $\left[\mathrm{Ru}(\mathrm{dcb})_{3}\right]^{2+}$ (where dcb is 4,4 '-dicarboxylic acid-2,2'-bipyridine). ${ }^{29,30}$ The sensitization strategy in this case is similar to that used successfully in dye-sensitized photoelectrochemical cells, ${ }^{31}$ and in colloidal semiconductor systems. ${ }^{32}$ Visible-light excitation produces the MLCT excited state, $\left[\mathrm{Ru}(\mathrm{dcb})_{3}\right]^{2+*}$, which is capable of injecting an electron into the conduction band (CB) of the semiconducting sheets. Spectra obtained by transient diffuse reflectance/laser flash photolysis experiments $(532 \mathrm{~nm}$ pulsed laser excitation) displayed a bleach from $400-600 \mathrm{~nm}$, consistent with formation of $\left[\mathrm{Ru}(\mathrm{dcb})_{3}\right]^{3+}$. The $\mathrm{Ru}^{3+} / \mathrm{e}^{-}(\mathrm{CB}, \mathrm{LMOS})$ charge-separated state recombines within 100 microseconds and follows biphasic kinetics. When the electron donor, $\mathrm{KI}$, is added to the system, $\left[\mathrm{Ru}(\mathrm{dcb})_{3}\right]^{3+}$ is no longer observed by flash photolysis; instead, a positive transient is observed when monitoring at $380 \mathrm{~nm}$, which is attributed to formation of $\mathrm{I}_{2}^{--}$according to the following reaction sequence:

$$
\begin{aligned}
{\left[\mathrm{Ru}(\mathrm{dcb})_{3}\right]^{2+*} } & \rightarrow\left[\mathrm{Ru}(\mathrm{dcb})_{3}\right]^{3+}+\mathrm{e}^{-}(\mathrm{CB}, \mathrm{LMOS}) \\
{\left[\mathrm{Ru}(\mathrm{dcb})_{3}\right]^{3+}+\mathrm{I}^{-} } & \rightarrow\left[\mathrm{Ru}(\mathrm{dcb})_{3}\right]^{2+}+\mathrm{I} \\
\mathrm{I}^{-}+\mathrm{I}^{-} & \rightarrow \mathrm{I}_{2}^{--} \\
2 \mathrm{I}_{2}^{--} & \rightarrow \mathrm{I}_{3}^{-}+\mathrm{I}^{-}
\end{aligned}
$$

Hence, the charge-separated state on the microsecond time-scale consists of $\mathrm{I}_{2}^{-} / \mathrm{e}^{-}(\mathrm{CB}$, LMOS), formed with a quantum yield of $\sim 10-15 \%$. On a seconds-minutes time-scale, only triiodide is observed showing that $\mathrm{I}_{2}^{--}$has disappeared either by disproportionation (equation $7 d)$ or by recombination with injected conduction band electrons ${ }^{33}$

In order to utilize the reducing equivalents of the charge-separated state for hydrogen evolution, the LMOS sheets were internally platinized. This process, which was first reported by Domen and coworkers, involves ion exchange of $\mathrm{Pt}\left(\mathrm{NH}_{3}\right)_{4}{ }^{2+}$ ions into the interlayer galleries followed by hydrogen reduction at $200-600^{\circ} \mathrm{C} .{ }^{34}$ Aqua regia treatment removes $\mathrm{Pt}$ from external sites. Because the solid is a cation exchanger, the resulting interlayer Pt clusters are inaccessible to anions. For example, $\left[\mathrm{Fe}(\mathrm{CN})_{6}\right]^{3-}$ is not reduced by molecular hydrogen in the presence of platinized sheets prepared by this method. This suggests that 
anionic species, such as $\mathrm{I}_{3}^{-}$, are incapable of intralayer diffusion and recombination with molecular hydrogen.

Hydrogen evolution was tested by photolyzing the above system using a Hg-Xe lamp. Upon light excitation, hydrogen and tri-iodide are formed in equimolar amounts. Importantly, hydrogen is formed in trace amounts in the absence of iodide and is not formed in the absence of $\left[\mathrm{Ru}(\mathrm{dcb})_{3}\right]^{2+}$. The initial quantum yield was determined to be $\sim 0.3 \%$; since this is a factor of 40 lower than that determined by flash photolysis, the major recombination pathway involves reduction of $\mathrm{I}_{3}^{-}$or $\mathrm{I}_{2}^{-}$by injected electrons in the semiconductor. Over time, the hydrogen evolution plateaus as the concentration of tri-iodide increases. By introducing fresh iodide solution and resuming the photolysis reaction, the initial hydrogen evolution rate is restored, supporting the claim that conduction band electrons also recombine with tri-iodide. Importantly, when the photolysis is stopped, the triiodide and hydrogen levels of the system do not change, indicating that the back reaction between photoproducts does not occur appreciably, presumably a result of their physical separation.

In subsequent studies, several LMOS's were studied as components in the above system: acid-exchanged titanates $\left(\mathrm{Na}_{3} \mathrm{Ti}_{3} \mathrm{O}_{7}\right.$ and $\left.\mathrm{K}_{2} \mathrm{Ti}_{4} \mathrm{O}_{9}\right)$, niobates $\left(\mathrm{KNb}_{3} \mathrm{O}_{8}\right.$ and $\left.\mathrm{K}_{4} \mathrm{Nb}_{6} \mathrm{O}_{17}\right)$, and titanoniobates $\left(\mathrm{KTiNbO}_{5}\right.$ and $\left.\mathrm{CsTi}_{2} \mathrm{NbO}_{7}\right){ }^{30}$ Following selective internal platinization, the LMOS's were fully acid-exchanged; suspensions prior to acid-exchange gave $\mathrm{pH}=9-10$ while those afterward gave $\mathrm{pH}=3-4$. Photochemical $(>400 \mathrm{~nm}$ ) hydrogen evolution was measured by gas chromatography for sensitized, internally platinized LMOS's in the presence of iodide. Only the niobates and the titanoniobates were found to produce stoichiometric amounts of hydrogen and triiodide, with $\mathrm{K}_{4} \mathrm{Nb}_{6} \mathrm{O}_{17}$ giving the highest initial quantum yield. In contrast, only trace amounts of hydrogen were detected for the two titanates under similar conditions. These results were attributed to the titanates having relatively positive conduction band edge energies compared to the niobates and titanoniobates. Theoretical predictions of the LMOS's band edge energies were made using concepts of electronegativity. The conduction band edge energy at the point of zero charge of a semiconductor, $E_{c s}{ }^{0}$, can be expressed by: ${ }^{35}$

$$
E_{c s}{ }^{0}=E^{\mathrm{e}}-X+1 / 2 E_{\mathrm{g}}
$$

where $E^{\mathrm{e}}$ is the energy of free electrons on the hydrogen scale $(\sim 4.5 \mathrm{eV}), X$ is the electronegativity of the semiconductor (calculated as the geometric mean of the electronegativities of its constituent atoms ${ }^{36}$ ), and $E_{\mathrm{g}}$ is the band gap energy of the semiconductor. Importantly, predicted values attained by this method have been shown to reasonably agree with experimentally determined flat band potentials. ${ }^{37}$ Using the above equation, the estimated conduction band edge energies for alkali LMOS's $(\sim-0.6-(-0.9) \mathrm{V}$, vs. NHE) tended to more negative than that of anatase $\mathrm{TiO}_{2}(-0.30 \mathrm{~V})$ while those of acidexchanged LMOS's tended to be more positive $(\sim 0 \mathrm{~V})$. Experimental support of this trend was obtained from $\mathrm{pH}$ dependent photoluminescence quenching experiments of $\left[\mathrm{Ru}(\mathrm{dcb})_{3}\right]^{2+}$ on $\mathrm{TiO}_{2}$ and on LMOS's. On $\mathrm{TiO}_{2}$, significant quenching was only observed when the $\mathrm{pH}$ was adjusted below 6, while that for the LMOS's begins at $\mathrm{pH}=4.5$. This result is in qualitative agreement with the LMOS's having more negative conduction band edge energies than $\mathrm{TiO}_{2}$. 
Interestingly, when the acid-exchanged niobates and titanoniobates were suspended in alkali iodide solutions, the $\mathrm{pH}$ of the suspension dropped from 3-4 to 1-2 due to exchange of protons for the alkali cations. This behavior was not observed for the titanates. X-Ray diffraction studies corroborated this, showing the presence of an additional interlayer spacing for the niobates and titanoniobates that have undergone alkali iodide treatment. In contrast, the titanates showed no changes in their diffraction patterns. Hence, the niobates and titanoniobates were partially proton-exchanged under the photolysis conditions used while the titanates remained fully acidified. As a result, the conduction band edge energies of the niobates and titanoniobates under the photolysis conditions should be more negative than that of the titanates. Furthermore, the slightly more acidic conditions used for the titanoniobates and niobates pushes the water/hydrogen reduction potential more positive, favoring hydrogen evolution. It was concluded that the titanates did not evolve hydrogen effectively because injected electrons cannot reduce hydrogen and thus fall victim to recombination. Similar explanations were used in follow-up studies to explain the superior photochemical hydrogen evolution observed for zeolite $\mathrm{L}$ impregnated with $\mathrm{Nb}_{2} \mathrm{O}_{5}$ and $\mathrm{Pt}$ in the presence of the nonsacrificial electron donor, MDESA ${ }^{2-}$, as compared to that impregnated with $\mathrm{TiO}_{2}$ and $\mathrm{Pt}^{38}$

The hydrogen evolution rate showed an interesting dependence on the LMOS interlayer spacing. ${ }^{30}$ The spacing was varied by changing iodide's countercation, decreasing in the order $\mathrm{Na}<\mathrm{Li}<\mathrm{Cs}<\mathrm{K}<\mathrm{H}^{39}$ The evolution rate increased in the same order, suggesting a competition exists between charge recombination and electron tunneling between layers. In layered LMOS system, the photosensitizer is adsorbed only on the external surface; thus, injected electrons reach Pt deposits faster when the interlayer spacing is small.

Another technique that can potentially reduce the rate of charge recombination involves blocking access of $\mathrm{I}_{2}^{--}$and/or $\mathrm{I}_{3}^{-}$to the LMOS surface. This was initially attempted by adsorbing alkyl phosphonates to $\left[\mathrm{Ru}(\mathrm{dcb})_{3}\right]^{2+}$-sensitized LMOS surfaces. Unfortunately, this resulted in significant sensitizer desorption under aqueous conditions. In order to circumvent this problem, a subsequent study employed a sensitizer that attaches itself to the LMOS surface through an aryl phosphonate linkage. ${ }^{40}$ Two polyanionic surface modifiers were examined, $\left[\mathrm{TiNbO}_{5}\right]_{\mathrm{n}}{ }^{\mathrm{n}-}$ and poly(styrenesulfonate) (PSS). Since the sensitizer imparts a positive charge to the unmodified LMOS surface, it is possible to deposit an anionic layer on top. Treatment of a sensitized surface $(1.43 \mu \mathrm{mol} / \mathrm{g}$ LMOS) with excess aqueous PSS resulted in a surface coverage of $5.25 \mu \mathrm{mol}$ PSS/g LMOS, indicating that the PSS layer overcompensates the charge of the sensitizer and provides a net negative charge to the surface. Both $\left[\mathrm{TiNbO}_{5}\right]_{\mathrm{n}}^{\mathrm{n}-}$ - and PSS were shown to increase the initial hydrogen evolution rate by a factor of 3 and 5, respectively (Figure 8). In the case of PSS, the initial rate corresponds to a quantum yield of $3 \%$. The polyanionic layer presumably assists in excluding redox-active species like $\mathrm{I}_{2}{ }^{-}$and $\mathrm{I}_{3}{ }^{-}$from the surface, thus decreasing the rate of charge recombination between these species and the injected electrons within the LMOS structure. This idea is supported by transient diffuse reflectance spectra obtained with and without PSS (Figure 10). The decays for charge recombination are well-described by a second-order kinetic model with rate constants of $3.17( \pm 0.03) \times 10^{7} \mathrm{M}^{-1} \mathrm{~s}^{-1}$ and $3.01( \pm 0.03) \mathrm{X}$ $10^{6} \mathrm{M}^{-1} \mathrm{~s}^{-1}$ for the unmodified and PSS-modified samples, respectively. While the actual values of these rate constants depend on an assumption about the pathlength of the analyzing light, the ratio of rate constants (approximately 10) does not, and is in semi-quantitative agreement with the enhanced hydrogen evolution rate found in the presence of PSS. 
The timescale of charge recombination is several milliseconds in the PSS-modified system. It follows that in order to replace iodide by water as the electron donor, one would need to couple this system to an oxygen evolving catalyst that could turn over quite rapidly. Alternatively, it may be possible to modify the solid to increase the rate of electron transfer from the outer surface, which is where electrons are injected, to interlayer Pt clusters. The low quantum yield for hydrogen evolution indicates that the timescale of this process is long (tens to hundreds of milliseconds) in LMOS systems, where electronic coupling between sheets is relatively weak.
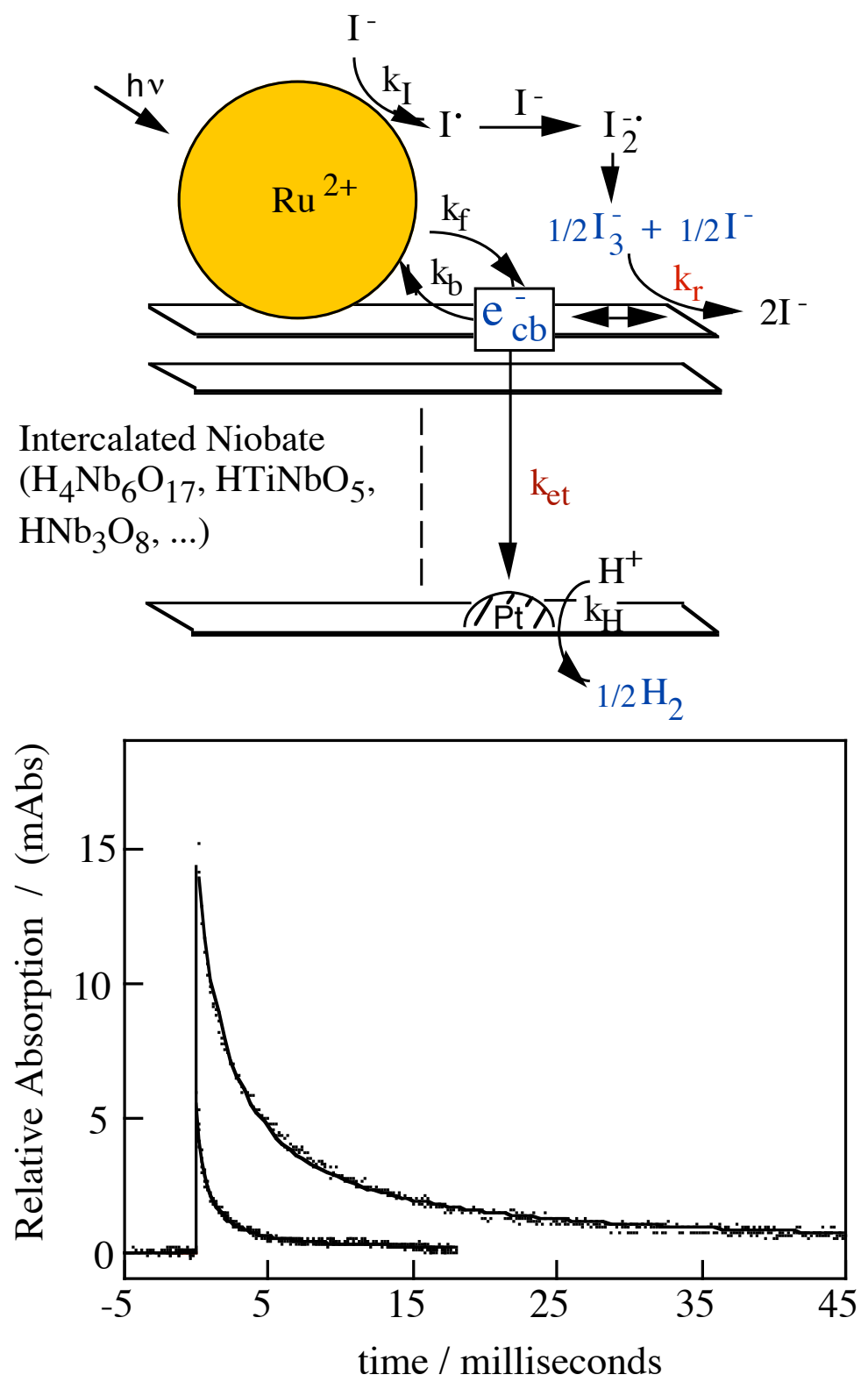

Figure 10. Top: Schematic drawing of an internally platinized, sensitized LMOS system showing kinetic pathways for photoinduced charge injection, charge recombination, and hydrogen evolution from iodide solution. Bottom: Average of 20 transient diffuse reflectance traces, acquired at $380 \mathrm{~nm}$, for $\mathrm{K}_{4-\mathrm{x}} \mathrm{H}_{\mathrm{X}} \mathrm{Nb}_{6} \mathrm{O}_{17}$ sensitized by (bpy) $2 \mathrm{Ru}(4-(2,2$ '-bipyrid-4yl)- phenylphosphonic acid, and for a similar sample modified with PSS, showing the difference in timescales for the charge recombination reaction of $\mathrm{e}_{\mathrm{cb}}$ and $\mathrm{I}_{3}{ }^{-}$. Second order fits (solid lines) are superimposed on the data points. 
b. Zeolite-Based Systems for Photochemical Hydrogen Evolution. A second non-sacrificial photochemical system, which operates on similar principles, was prepared by loading mordenite crystallites with $\mathrm{Pt}$ clusters and oxide semiconductors $\left(\mathrm{TiO}_{2}\right.$ and $\mathrm{Nb}_{2} \mathrm{O}_{5}$ ), and adsorbing the size-excluded dye $\mathrm{RuL}_{3}{ }^{2+}$ to the oxide. Mordenite is a linear channel zeolite which has good stability under the mildly acidic conditions used in the preparation and testing of these composites. The two oxide semiconductors were prepared by vapor phase and sol-gel deposition of molecular precursors $\mathrm{TiCl}_{4}, \mathrm{NbCl}_{5}$, $\mathrm{Ti}\left(\mathrm{OCH}\left(\mathrm{CH}_{3}\right)_{2}\right)_{4}$, and $\mathrm{Nb}(\mathrm{OMe})_{5} \cdot \mathrm{py}$. BET surface area measurements and ion-exchange experiments using methylviologen $\left(\mathrm{MV}^{2+}\right)$ showed that $\mathrm{TiO}_{2}$ or $\mathrm{Nb}_{2} \mathrm{O}_{5}$ is deposited within the one-dimensional channels, except in the case of $\operatorname{Ti}\left(\mathrm{OCH}\left(\mathrm{CH}_{3}\right)_{2}\right)_{4}$, where the precursor is size-excluded. Dye adsorption measurements showed that relatively little $\mathrm{Nb}_{2} \mathrm{O}_{5}$ is accessible at the external surface of the zeolite when the $\mathrm{Nb}(\mathrm{OMe})_{5} \cdot \mathrm{py}$ precursor was used. UV photolysis experiments in the presence of sacrificial electron donors established that the composites prepared from $\mathrm{TiCl}_{4}$ and $\mathrm{NbCl}_{5}$ had much higher rates of hydrogen evolution than those made from $\mathrm{Ti}\left(\mathrm{OCH}\left(\mathrm{CH}_{3}\right)_{2}\right)_{4}$ or $\mathrm{Nb}(\mathrm{OMe})_{5}$. py. Presumably this is because of a greater fraction of the semiconductor connects the external solution, which contains the electron donor, with the intrazeolitic Pt clusters.

When these composites were sensitized with $\mathrm{RuL}_{3}{ }^{2+}$, visible light excitation resulted in the expected efficient charge injection and slow (submillisecond) charge recombination. Photosensitized hydrogen evolution was also studied with both sacrificial (EDTA, triethanolamine, cysteine, dithiothreitol) and non-sacrificial (I-, HQDS ${ }^{2-}, \mathrm{HQS}^{-}$, MDESA $^{2-}$, TESPD ${ }^{4-}$ ) electron donors. The most important trend that emerged from these

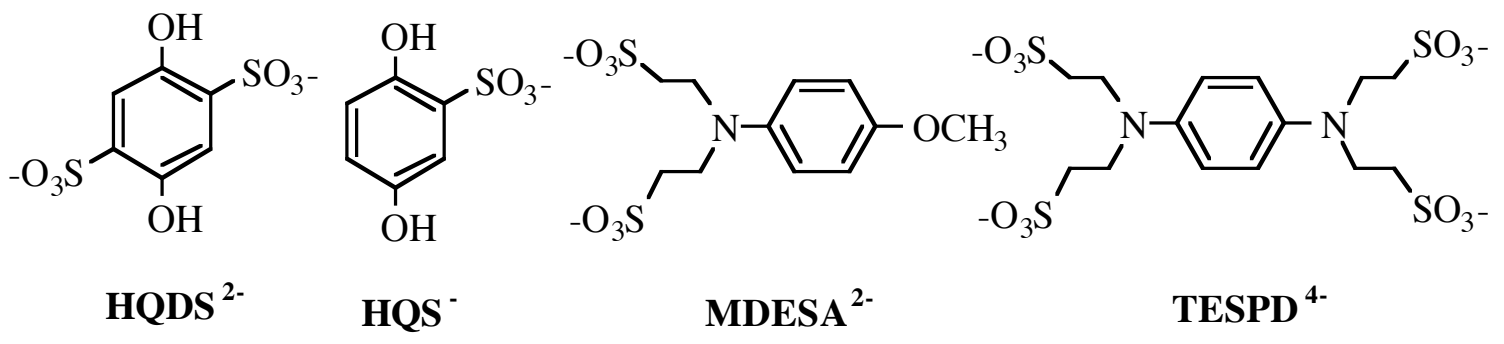

studies was that while hydrogen evolution occurred with both intrazeolitic semiconductors $\left(\mathrm{TiO}_{2}\right.$ and $\left.\mathrm{Nb}_{2} \mathrm{O}_{5}\right)$ using sacrificial donors, only $\mathrm{Nb}_{2} \mathrm{O}_{5}$-containing composites evolved hydrogen with anionic non-sacrificial donors. These results are entirely consistent with our observations with layered metal oxide semiconductors, in which the sensitized titanates, because of their more positive conduction band edge potentials, do not photochemically decompose HI solutions. Another parallel between the lamellar and intrazeolitic semiconductors is that the mordenite/ $\mathrm{TiO}_{2} / \mathrm{Pt}$ composites mediate the dark recombination reaction between ferricyanide and hydrogen, whereas the analogous $\mathrm{Nb}_{2} \mathrm{O}_{5}$ composites do not.

b. Nanoscale Niobium Oxide Tubules. As noted above, one of the objectives of our work has been to adapt the layer-by-layer assembly technique to the preparation of 
oxide semiconductor multilayer films for photochemical hydrogen evolution from nonsacrificial electron donors. We prepared assemblies of the type shown in Figure 11, and studied the kinetics of electron transfer in them by flash photolysis techniques. In this

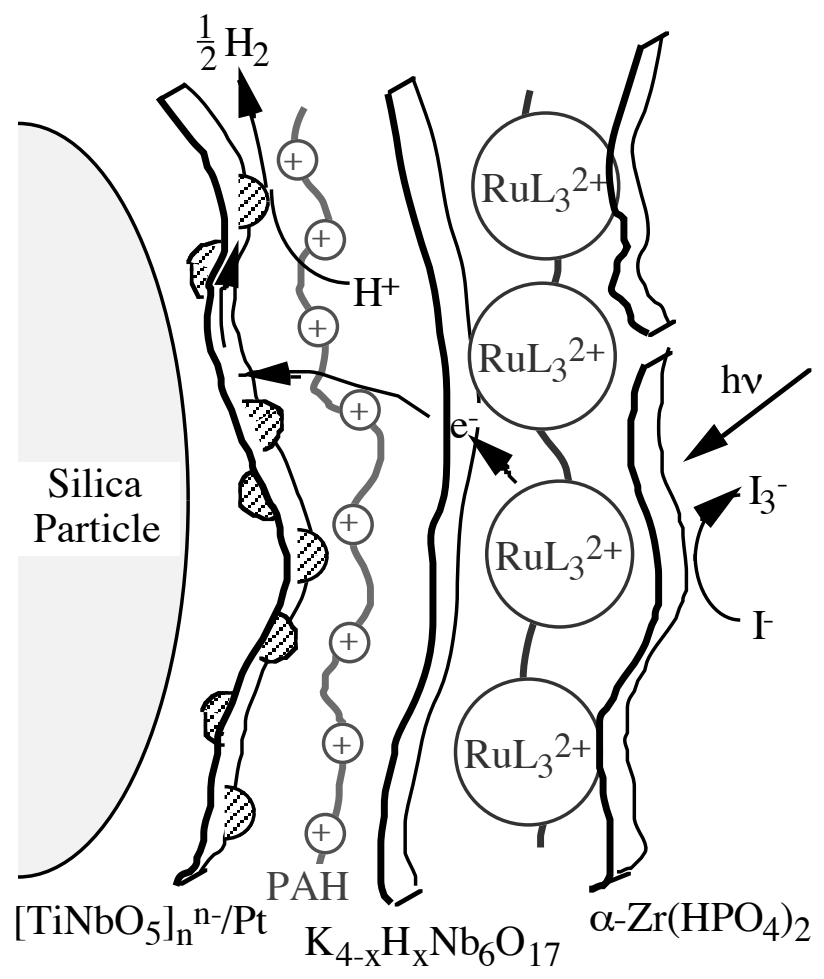

Figure 11. Multilayer oxide semiconductor system for HI photolysis.

kind of thin film assembly, a vectorial flow of electrons from the niobate to the platinized titanoniobate sheets is expected because of the more negative valence band-edge potential of the former. The outer polyanion layer (e.g., PSS or $\mathrm{Zr}\left(\mathrm{HPO}_{4}\right)_{2}$ ) provides a barrier to back electron transfer between the niobate sheet and the oxidized donor anion.

Constructing complex assemblies of this type required us to control the colloid chemistry of different types of sheets, and to characterize the structure of the resulting "onion" structures. In the course of this work we discovered that $\mathrm{K}_{4-\mathrm{x}} \mathrm{H}_{\mathrm{x}} \mathrm{Nb}_{6} \mathrm{O}_{17}$ has rather unusual colloidal behavior. When exfoliated with $\mathrm{TBA}^{+} \mathrm{OH}^{-}$, the colloid exists first as bilayer sheets, and then converts to a single sheet colloid which spontaneously curls into tubules that are $15-30 \mathrm{~nm}$ in diameter and several hundred $\mathrm{nm}$ in length. Cross sectional TEM clearly establishes the tubular nature of these colloids. By varying the colloid concentration, the sheets can be made to roll (high concentration) and unroll (low concentration) reversibly, as shown in Figure 12. ${ }^{41}$
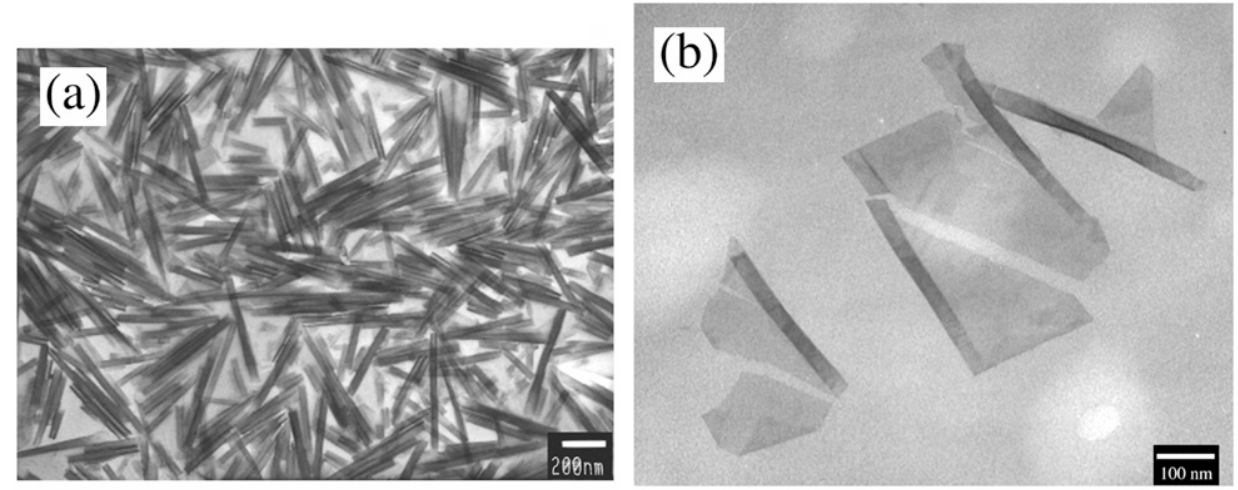

Figure 12. TEM images of (a) high and (b) low concentration $\mathrm{K}_{4-\mathrm{x}} \mathrm{H}_{\mathrm{x}} \mathrm{Nb}_{6} \mathrm{O}_{17}$ colloids.

The coiled shape can also be locked in permanently by addition of acid or $\mathrm{K}^{+}$cations. The curling of these colloids appears to be driven by the inherent asymmetry of the 
sheets, a feature that is absent in electronically similar, "flat" colloids derived from $\mathrm{KNb}_{3} \mathrm{O}_{8}$ and $\mathrm{KCa}_{2} \mathrm{Nb}_{3} \mathrm{O}_{10}$.

\section{Colloidal Catalysts for Photochemical Oxygen Evolution}

a. Colloidal Iridium Oxide and Related Composite Systems. One of the biggest obstacles to achieving efficient photochemical water splitting has been the inability to identify an effective, selective $\mathrm{O}_{2}$ evolving system. Since evolution of $\mathrm{O}_{2}$ from $\mathrm{H}_{2} \mathrm{O}$ requires four oxidizing equivalents (reaction 10), this process is kinetically more

$$
2 \mathrm{H}_{2} \mathrm{O} \rightarrow \mathrm{O}_{2}+4 \mathrm{H}^{+}+4 \mathrm{e}^{-}
$$

demanding than the hydrogen evolution half reaction. While there has been encouraging progress with transition metal oxo-bridged clusters as homogeneous oxygen evolution catalysts, ${ }^{42-48}$ none have turnover rates faster than about $0.01 \mathrm{~s}^{-1}$. The exception is the $\mathrm{Mn}_{3} \mathrm{CaO}_{4}$ cluster of photosystem II in natural photosynthesis, which has a turnover rate on the order of $10^{3} \mathrm{~s}^{-1}$. 49

It has long been known that colloidal and bulk $\mathrm{RuO}_{2}$ and $\mathrm{IrO}_{2}$ are capable of heterogeneously catalyzing water oxidation in the presence of $\left[\mathrm{Ru}(\mathrm{bpy})_{3}\right]^{2+}$ photosensitizer and the sacrificial electron acceptor, $\mathrm{S}_{2} \mathrm{O}_{8}{ }^{2-}$, via photocatalytic cycle (11). ${ }^{50-54}$ The mechanism involves the following elementary steps:

$$
\begin{gathered}
{\left[\mathrm{Ru}(\text { bpy })_{3}\right]^{2+} \stackrel{h v}{\longrightarrow}\left[\mathrm{Ru}(\text { bpy })_{3}\right]^{2+*}} \\
{\left[\mathrm{Ru}(\mathrm{bpy})_{3}\right]^{2+*}+\mathrm{S}_{2} \mathrm{O}_{8}^{2-} \rightarrow\left[\mathrm{Ru}(\text { bpy })_{3}\right]^{3+}+\mathrm{SO}_{4}^{--}+\mathrm{SO}_{4}^{2-}} \\
{\left[\mathrm{Ru}(\text { bpy })_{3}\right]^{2+}+\mathrm{SO}_{4}^{--} \rightarrow\left[\mathrm{Ru}(\text { bpy })_{3}\right]^{3+}+\mathrm{SO}_{4}^{2-}} \\
2\left[\mathrm{Ru}(\text { bpy })_{3}\right]^{3+}+2 \mathrm{MO}_{2}(\mathrm{red}) \rightarrow 2\left[\mathrm{Ru}(\text { bpy })_{3}\right]^{2+}+2 \mathrm{MO}_{2}(\text { ox }) \\
2 \mathrm{MO}_{2}(\mathrm{ox})+\mathrm{H}_{2} \mathrm{O} \rightarrow 2 \mathrm{MO}_{2}(\text { red })+1 / 2 \mathrm{O}_{2}+2 \mathrm{H}^{+}
\end{gathered}
$$

In the absence of any of the above components, no $\mathrm{O}_{2}$ is observed. The initial quantum yields for $\mathrm{O}_{2}$ evolution have been found to reach $40-60 \%$ under optimized conditions. ${ }^{55}$ The $\left[\mathrm{Ru}(\mathrm{bpy})_{3}\right]^{2+}$ photosensitizer, however, is irreversibly consumed during the photocatalytic cycle, and in phosphate-containing buffers its turnover number does not exceed 80 even under the most optimized conditions. Decomposition of the sensitizer is believed to involve nucleophilic attack by $\mathrm{H}_{2} \mathrm{O}$ upon one or more of $\left[\mathrm{Ru}(\mathrm{bpy})_{3}\right]^{3+} \mathrm{s}$ bipyridine ligands. ${ }^{56}$ Whereas both $\mathrm{RuO}_{2}$ and $\mathrm{IrO}_{2}$ can catalyze $\mathrm{O}_{2}$ evolution, bulk and colloidal $\mathrm{IrO}_{2}$ has been found to be more stable than $\mathrm{RuO}_{2}$, which undergoes anodic corrosion. $^{57}$

Colloidal $\mathrm{IrO}_{2}$ is a particularly interesting colloidal catalyst because of its stability, and the ease of analysis of the photocatalytic cycle (10) with simple UV-Vis spectrophotometry. ${ }^{58}$ Colloidal catalysts also typically have a surface charge that can be used to incorporate them into photosynthetic assemblies constructed from inorganic sheets and organic polyelectrolytes. As a result, the photocatalytic potential of $\mathrm{IrO}_{2}$ colloids has been further investigated in our laboratory beyond the previous studies by Harrimann and coworkers.

In photoredox cycle (11), protons are released when $\mathrm{O}_{2}$ is evolved, and this causes a decrease in the $\mathrm{pH}$ of the system. Harrimann and coworkers have shown that the 
reduction potential of $\mathrm{IrO}_{2}$ colloids shifts positively as the $\mathrm{pH}$ of the external solution is lowered. ${ }^{59}$ At lower $\mathrm{pH}$, the driving force for reaction $10 \mathrm{~d}$ decreases, leading to slower electron transfer between the photosensitizer and $\mathrm{IrO}_{2}($ red). At higher $\mathrm{pH}$, nucleophilic attack on the oxidized $\mathrm{Ru}(\mathrm{III})$ complex becomes more rapid. Hence, it is advantageous to control the $\mathrm{pH}$ of the photocatalytic system. Indeed, Harriman and coworkers found that the rate of $\mathrm{O}_{2}$ evolution is optimal at $\mathrm{pH} \sim 5$ and decreases below and above this value.

We investigated several buffer candidates and found that both the photosensitizer decomposition rate and the turnover number depended sensitively on the composition of the buffer. For $\mathrm{KH}_{2} \mathrm{PO}_{4} / \mathrm{Na}_{2} \mathrm{~B}_{4} \mathrm{O}_{7}$ buffer, the turnover number depended significantly on the buffer concentration, reaching a maximum at $0.011 \mathrm{M}$. Further experiments in which $\left[\mathrm{Ru}(\mathrm{bpy})_{3}\right]^{2+}$ was irradiated in the presence of $\mathrm{S}_{2} \mathrm{O}_{8}^{2-}$ and absence of $\mathrm{IrO}_{2}$ showed that $\left[\mathrm{Ru}(\mathrm{bpy})_{3}\right]^{3+}$ is rapidly decomposed at higher buffer concentrations. Similar experiments using either $\mathrm{KH}_{2} \mathrm{PO}_{4}$ or $\mathrm{Na}_{2} \mathrm{~B}_{4} \mathrm{O}_{7}$ showed that the culprit was the $\mathrm{KH}_{2} \mathrm{PO}_{4}$ component of the buffer. Subsequent studies focused on buffers that contain only weakly coordinating inorganic anions, such as $\mathrm{Na}_{2} \mathrm{SiF}_{6} / \mathrm{Na}_{2} \mathrm{~B}_{4} \mathrm{O}_{7}$ and $\mathrm{Na}_{2} \mathrm{SiF}_{6} / \mathrm{NaHCO}_{3}$. The latter showed a sensitizer turnover number of 290 as compared with 100 for the former, as well as a higher average rate of oxygen evolution. After $\sim 30$ minutes, the $\mathrm{O}_{2}$ evolution plateaus due to complete consumption of the $\mathrm{S}_{2} \mathrm{O}_{8}{ }^{2-}$ sacrificial acceptor. By adding additional $\mathrm{S}_{2} \mathrm{O}_{8}^{2-}$ and more $\mathrm{HCO}_{3}^{-}$to bring the $\mathrm{pH}$ from 5.0 to 5.4, $\mathrm{O}_{2}$ evolution resumes upon photolysis, albeit with a lower yield and lower initial rate. The lower rate of the second photolysis was ascribed to $\sim 50 \%$ decomposition of the sensitizer during the initial photolysis.

Several attempts were made to determine why bicarbonate gave superior performance relative to borate. Both buffers were effective at maintaining the $\mathrm{pH}$ above 5 during the entirety of the photolysis and both gave similar $\left[\mathrm{Ru}(\mathrm{bpy})_{3}\right]^{2+}$ observed rate constants for decomposition in the absence of $\mathrm{IrO}_{2}$. In addition, the rate during the initial 20 minutes of the photolysis was similar for both buffers. The latter finding argues that the enhancement is not a result of bicarbonate-induced acceleration of reactions $11 \mathrm{~d}$ and 10e. Since the $\mathrm{IrO}_{2}$ colloid is negatively charged at $\mathrm{pH}>2$, the buffers may be influencing favorable adsorption of $\left[\mathrm{Ru}(\mathrm{bpy})_{3}\right]^{2+}$. However, surface coverages of $\left[\mathrm{Ru}(\mathrm{bpy})_{3}\right]^{2+}$ on $\mathrm{IrO}_{2} / 4$-aminobutyldimethylmethoxysilane/ $\mathrm{SiO}_{2}$ were similar in the presence of both buffers, suggesting that the buffers do not significantly influence sensitizer adsorption.

From the above studies, it was concluded that decomposition of $\left[\mathrm{Ru}(\mathrm{bpy})_{3}\right]^{3+}$ prevents achievement of turnover numbers $>290$. Under photochemical conditions, a significant portion of $\left[\mathrm{Ru}(\mathrm{bpy})_{3}\right]^{3+}$ is present in free solution because excited state oxidation by $\mathrm{S}_{2} \mathrm{O}_{8}{ }^{2-}$ is rapid. $\left[\mathrm{Ru}(\mathrm{bpy})_{3}\right]^{3+}$ molecules that are adsorbed to the $\mathrm{IrO}_{2}$ are less susceptible to decomposition because they are more rapidly reduced by the colloid. In light of this finding, Hara et al. synthesized $\mathrm{IrO}_{2}$ colloidal particles in the presence of Nafion, a perfluorinated anionic polyelectrolyte that contains sulfonate pendants. ${ }^{60}$ Photolysis reactions comparing the $\left[\mathrm{Ru}(\mathrm{bpy})_{3}\right]^{2+}-\mathrm{IrO}_{2}$ colloid system (i.e. free colloid) with the Nafion-stabilized $\mathrm{IrO}_{2}$ system were performed under identical conditions. In both systems, the initial $\mathrm{O}_{2}$ evolution rates plateau at high $\left[\mathrm{Ru}(\mathrm{bpy})_{3}\right]^{2+}$ concentration, resembling Langmuir adsorption isotherm behavior. For the Nafion system, this plateau begins at $\sim 2 \times 10^{-4} \mathrm{M}\left[\mathrm{Ru}(\mathrm{bpy})_{3}\right]^{2+}$ at which point the initial rate is $\sim 1.6$ times that for the free-colloid system. The highest quantum yields for the Nafion system and free colloid 
system were $73 \%$ and $45 \%$, respectively. Meanwhile, the turnover number for both systems reaches a maximum and then falls off at higher $\left[\mathrm{Ru}(\mathrm{bpy})_{3}\right]^{2+}$ concentrations, consistent with competition between $\mathrm{O}_{2}$ evolution and sensitizer decomposition at higher $\left[\mathrm{Ru}(\text { bpy })_{3}\right]^{2+}$ concentrations. The $\mathrm{O}_{2}$ evolution rates were also examined as a function of the incident light intensity at fixed $\left[\mathrm{Ru}(\mathrm{bpy})_{3}\right]^{2+}$ concentration. For the free colloid system, the rate plateaus at high light intensities suggesting limitations by $\left[\mathrm{IrO}_{2}\right]$. No plateau was observed for the Nafion system, indicating that oxygen evolution is lightlimited. The superior performance of the Nafion-stabilized system was tentatively attributed to Nafion-induced enhancement of $\left[\mathrm{Ru}(\mathrm{bpy})_{3}\right]^{2+} / \mathrm{IrO}_{2}$ adsorption which aids in preventing unwanted sensitizer decomposition.

Photochemical water oxidation was further investigated using $\mathrm{IrO}_{2}$ colloid supported on silica particles (avg. diameter $=70 \mathrm{~nm}$ ). ${ }^{61}$ By using the cationic $\mathrm{Ru}$ (II) poly(pyridyl) polymer, $\left[\mathrm{Ru}^{2+}\right]_{9}$, sensitized $\mathrm{IrO}_{2}$ containing composites (Figure 9) were made by the LBL technique. Two different multilayer sequences were studied. In the first case, anionic $\mathrm{SiO}_{2}$ was first treated with $\left[\mathrm{Al}_{13} \mathrm{O}_{4}(\mathrm{OH})_{24}\left(\mathrm{H}_{2} \mathrm{O}\right)_{12}\right]^{7+}$ (Keggin) ions followed sequentially by the $\mathrm{IrO}_{2}$ colloid and $\left[\mathrm{Ru}^{2+}\right]_{9}$. This system showed low the photocatalytic activity which was attributed to poor physical contact between $\left[\mathrm{Ru}^{2+}\right]_{9}$ and the $\mathrm{IrO}_{2}$ particles. In the second case, a solution containing $\left[\mathrm{Ru}^{2+}\right]_{9}$ and $\mathrm{IrO}_{2}$ colloid was first added to a $\mathrm{Na}_{2} \mathrm{SiF}_{6} / \mathrm{NaHCO}_{3}$ buffer solution, which in turn, was immobilized on the silica support. This system showed similar photocatalytic activity to $\left[\mathrm{Ru}^{2+}\right]_{9}-\mathrm{IrO}_{2}$ colloidal solutions. Although both systems showed lower $\mathrm{O}_{2}$ evolution rates $(0.3$ $\mu \mathrm{mol} / \mathrm{min})$ and lower turnover numbers $(\sim 90)$ compared to that of the optimized $\left[\mathrm{Ru}(\mathrm{bpy})_{3}\right]^{2+}-\mathrm{IrO}_{2}$ colloid system, silica-supported $\left[\mathrm{Ru}^{2+}\right]_{9}-\mathrm{IrO}_{2}$ does represent an integrated chemical system for photochemical oxygen evolution, which could in principle be coupled to a microheterogeneous hydrogen evolving photosystem.
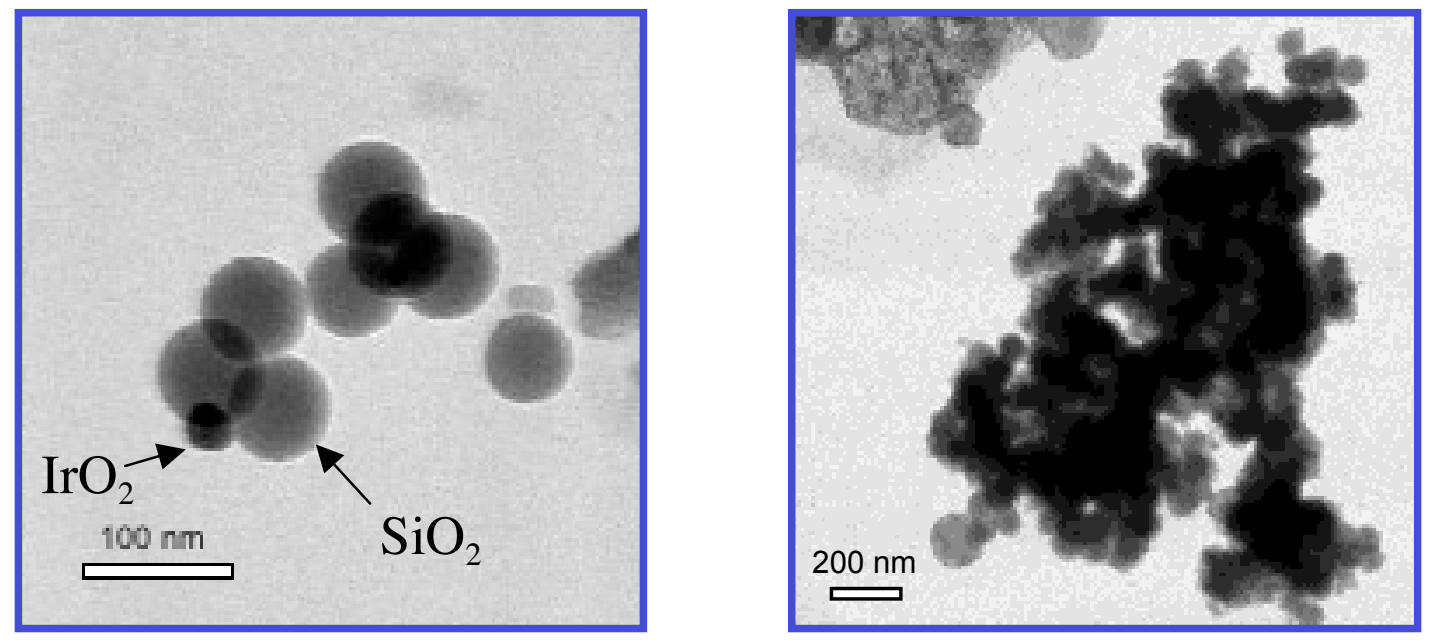


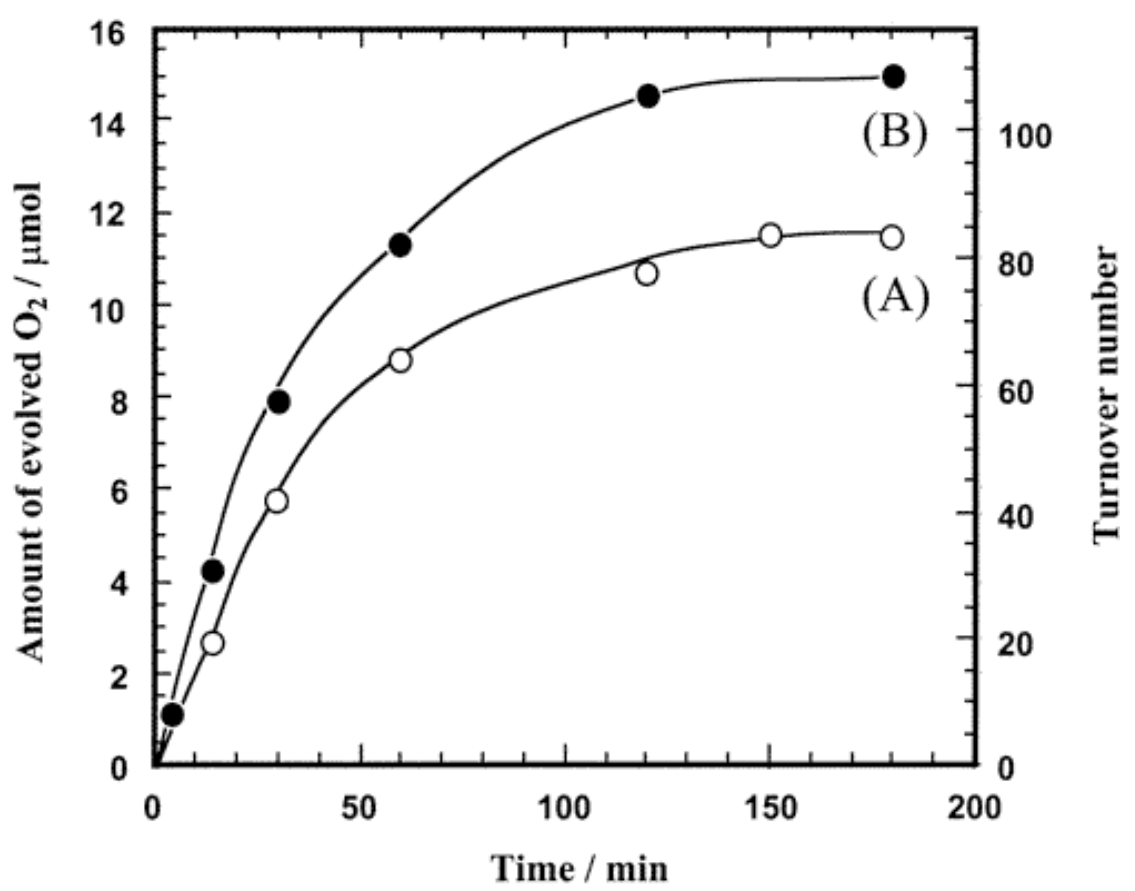

Figure 13. Top: TEM images of $\mathrm{IrO}_{2} / \mathrm{Keggin} / \mathrm{SiO}_{2}$ and $\left[\mathrm{Ru}^{2+}\right]_{9} / \mathrm{IrO}_{2} / \mathrm{Keggin} / \mathrm{SiO}_{2}$. Bottom: Time course of $\mathrm{O}_{2}$ evolution from $\left[\mathrm{Ru}^{2+}\right]_{9}-\mathrm{IrO}_{2} / \mathrm{SiO}_{2}$ samples: (A) $\left[\mathrm{Ru}^{2+}\right]_{9}-\mathrm{IrO}_{2} / \mathrm{SiO}_{2}$; (B) $\left[\mathrm{Ru}^{2+}\right]_{9}$-colloidal $\mathrm{IrO}_{2}$.

b. A High Throughput Method for Optimizing Photocatalysts. The problem of coupling hydrogen- and oxyen-evolving photocatalytic systems for overall water splitting requires them to function under the same conditions $(\mathrm{pH}$, buffer composition, etc.). Efficient water splitting would also require catalysts that turn over fast enough to compete kinetically with back electron transfer reactions. In order to optimize the turnover rate of colloidal $\mathrm{IrO}_{2}$ catalysts and rapidly explore their behavior under different conditions, we developed a simple high throughput screening method. The method is based on the retention of $\left[\mathrm{Ru}(\mathrm{bpy})_{3}\right]^{2+}$ absorbance or emission under continuous photolysis in $\mathrm{IrO}_{2}$ /persulfate solutions. ${ }^{62}$ Because the destruction of the sensitizer by nucleophilic attack on the $\mathrm{Ru}(\mathrm{III})$ complex competes kinetically with catalytic oxygen evolution in cycle (10), better catalysts or better catalytic conditions correspond to longer retention of $\left[\mathrm{Ru}(\mathrm{bpy})_{3}\right]^{2+}$ spectral properties. Figure 14 illustrates the screening method, which utilizes standard 96-well plates and a conventional plate reader. Interestingly, in $\mathrm{Na}_{2} \mathrm{SiF}_{6} / \mathrm{NaHCO}_{3}$ buffer we found higher turnover numbers at higher $\mathrm{pH}(\mathrm{pH} \geq 7.0)$. At this $\mathrm{pH}$ the $\mathrm{SiF}_{6}^{2-}$ ion is slowly hydrolyzed to colloidal silica and the system begins to resemble the microheterogeneous sensitizer/colloidal catalyst/silica system shown in Fig. 13. Direct measurements of the $\mathrm{Ru}(\mathrm{III})$ lifetime in this medium shows that the decomposition rate of the oxidized sensitzer is actually lower at higher $\mathrm{pH}$, probably because of the interaction of the $\left[\mathrm{Ru}(\mathrm{bpy})_{3}\right]^{3+2+}$ complex with the anionic silica surface. 


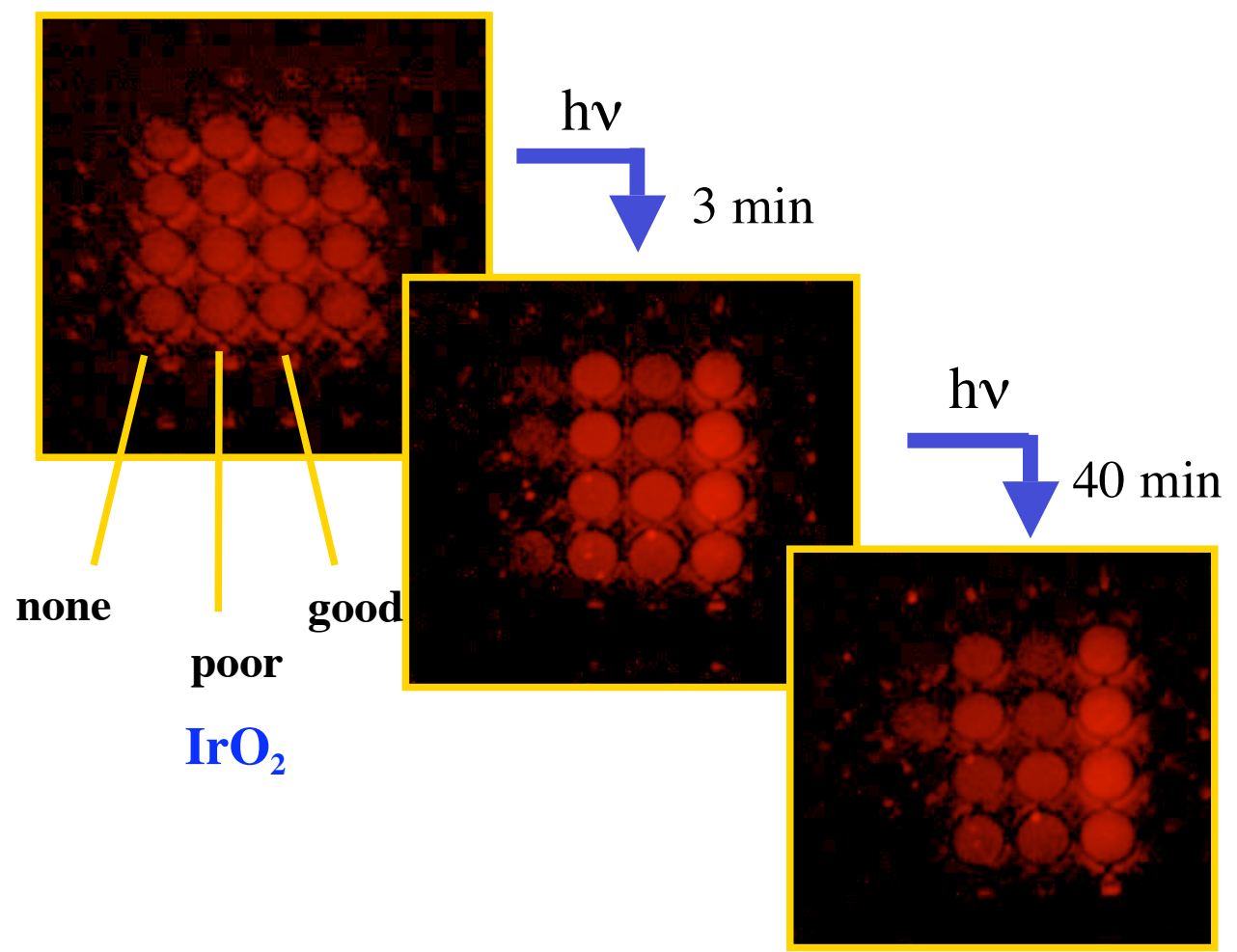

Figure 14. Emission snapshots of a 96-well plate containing sensitizer-colloid-sacrificial acceptor reaction solutions: lane 1 , no colloid; lane 2 , low activity colloid; lane 3 , higher activity colloid; and lane 4, no sacrificial acceptor. The emission images were aquired through a red filter by illuminating with $450 \mathrm{~nm}$ light, after illuminating the well plate for the specified amount of time on an overhead projector. The emission signal is retained longer with better oxygen evolution catalysts.

Determining the rate-limiting step in the photocatalytic cycle (11) is an essential step towards answering the question of whether colloidal $\mathrm{IrO}_{2}$ catalysts could be useful for overall photocatalytic water splitting. For instance, if the slow step is electron transfer between $\left[\mathrm{Ru}(\mathrm{bpy})_{3}\right]^{3+}$ and $\mathrm{IrO}_{2}$ colloid, then the strategy for enhancing $\mathrm{O}_{2}$ evolution rates would be to improve the electronic coupling or to increase the driving force of the reaction by changing the ligands of the sensitizer. However, if the ratedetermining step is O-O bond formation or $\mathrm{M}-\mathrm{O}$ bond dissociation, then it would be beneficial to redesign the catalyst itself. With this goal is mind, we performed timeresolved UV-Vis spectrophotometry experiments, in which $\left[\mathrm{Ru}(\mathrm{bpy})_{3}\right]^{3+}$ is reduced by $\mathrm{IrO}_{2}$ colloid, and photochemical steady-state $\mathrm{O}_{2}$ evolution studies in both $\mathrm{H}_{2} \mathrm{O}$ and $\mathrm{D}_{2} \mathrm{O}$. ${ }^{63}$ In both sets of experiments, we observed a kinetic isotope effect (KIE) of 1.0, which contrasts the KIE's of 1.4 and 1.6 reported for the molecular $\mathrm{O}_{2}$ evolving complexes, cis,cis- $\left[\left[(\mathrm{bpy})_{2} \mathrm{Ru}\left(\mathrm{OH}_{2}\right)\right]_{2} \mathrm{O}\right]^{4+}$ and $\left[(\text { terpy })\left(\mathrm{H}_{2} \mathrm{O}\right) \mathrm{Mn}^{\mathrm{III}}(\mathrm{O})_{2}\left(\mathrm{OH}_{2}\right)(\text { terpy })\right]^{3+}$, respectively. This suggests that the rate determining step in water oxidation at $\mathrm{IrO}_{2}$ colloids is outer sphere electron transfer between the oxidized sensitizer and the colloid.

Time resolved studies confirmed that the oxygen evolution reaction follows second order kinetics, and that increasing the concentration of either reagent increases the reaction rate. This finding is consistent with an earlier observation by Harriman and coworkers that the rate of water oxidation by radiolytically oxidized $\mathrm{IrO}_{2}$ clusters is quite fast. ${ }^{64}$ Under the conditions normally used for photocatalytic cycle (11), the steady state 
concentration of photogenerated $\left[\mathrm{Ru}(\mathrm{bpy})_{3}\right]^{3+}$ is low and therefore the oxygen evolution rate is low. By using relatively high concentrations of the $\left[\mathrm{Ru}(\mathrm{bpy})_{3}\right]^{2+}$ sensitizer, oxidizing it photochemically to $\left[\mathrm{Ru}(\mathrm{bpy})_{3}\right]^{3+}$, and then injecting the $\mathrm{IrO}_{2}$ colloid we were able to reach site turnover rates of about $160 \mathrm{~s}^{-1}$, which corresponds to $\mathrm{O}_{2}$ evolution at a rate of about 40 molecules/s per surface Ir atom. This result is very encouraging for possible use of $\mathrm{IrO}_{2}$ colloids in water splitting systems. It also helps explain why supports for $\mathrm{IrO}_{2}$ such as Nafion, which is a good cation exchanger, lead to higher $\left[\mathrm{Ru}(\mathrm{bpy})_{3}\right]^{3+}$ turnover rates. Such supports serve to concentrate the oxidized sensitizer at the surface of the colloid, leading to a higher rate of electron transfer.

\section{Lamellar and Nanocrystalline Semiconductors}

a. Oxynitride and Fluoronitride Semiconductors. Our recent work in particlebased photocatalysis has sought to address the problem that wide bandgap oxides, such as $\mathrm{KTaO}_{3}$, are the only known materials that can catalyze the photolysis of water with high quantum yield $(>10 \%)$.

We synthesized the known oxynitrides $\mathrm{CaTaO}_{2} \mathrm{~N}$ and $\mathrm{SrTaO}_{2} \mathrm{~N}$, which are structurally very similar to $\mathrm{NaTaO}_{3}$ and $\mathrm{KTaO}_{3}$, respectively. LMTO-ASA band structure calculations, ${ }^{65}$ which are enabled by the fact that $\mathrm{O}$ and $\mathrm{N}$ atoms are ordered in the $\mathrm{SrTaO}_{2} \mathrm{~N}$ structure, ${ }^{66}$ were performed on $\mathrm{SrTaO}_{2} \mathrm{~N}$ and $\mathrm{KTaO}_{3}$. These calculations show a significant difference in the bandgap between $\mathrm{SrTaO}_{2} \mathrm{~N}$ and $\mathrm{KTaO}_{3}$, which can only be assessed qualitatively at the level of the LMTO calculations. From UV-visible diffuse reflectance spectra, we estimate indirect bandgaps of 2.90, 2.55, and $3.50 \mathrm{eV}$ for $\mathrm{CaTaO}_{2} \mathrm{~N}, \mathrm{SrTaO}_{2} \mathrm{~N}$, and $\mathrm{KTaO}_{3}$, respectively. The band structure calculations (see Figure 14) show, as expected, that the conduction band is composed primarily of $\mathrm{Ta} 5 \mathrm{~d}$ states. The nitrogen $2 p$ states lie at the top of the valence band, and are primarily responsible for narrowing the bandgap, relative to the analogous oxide.

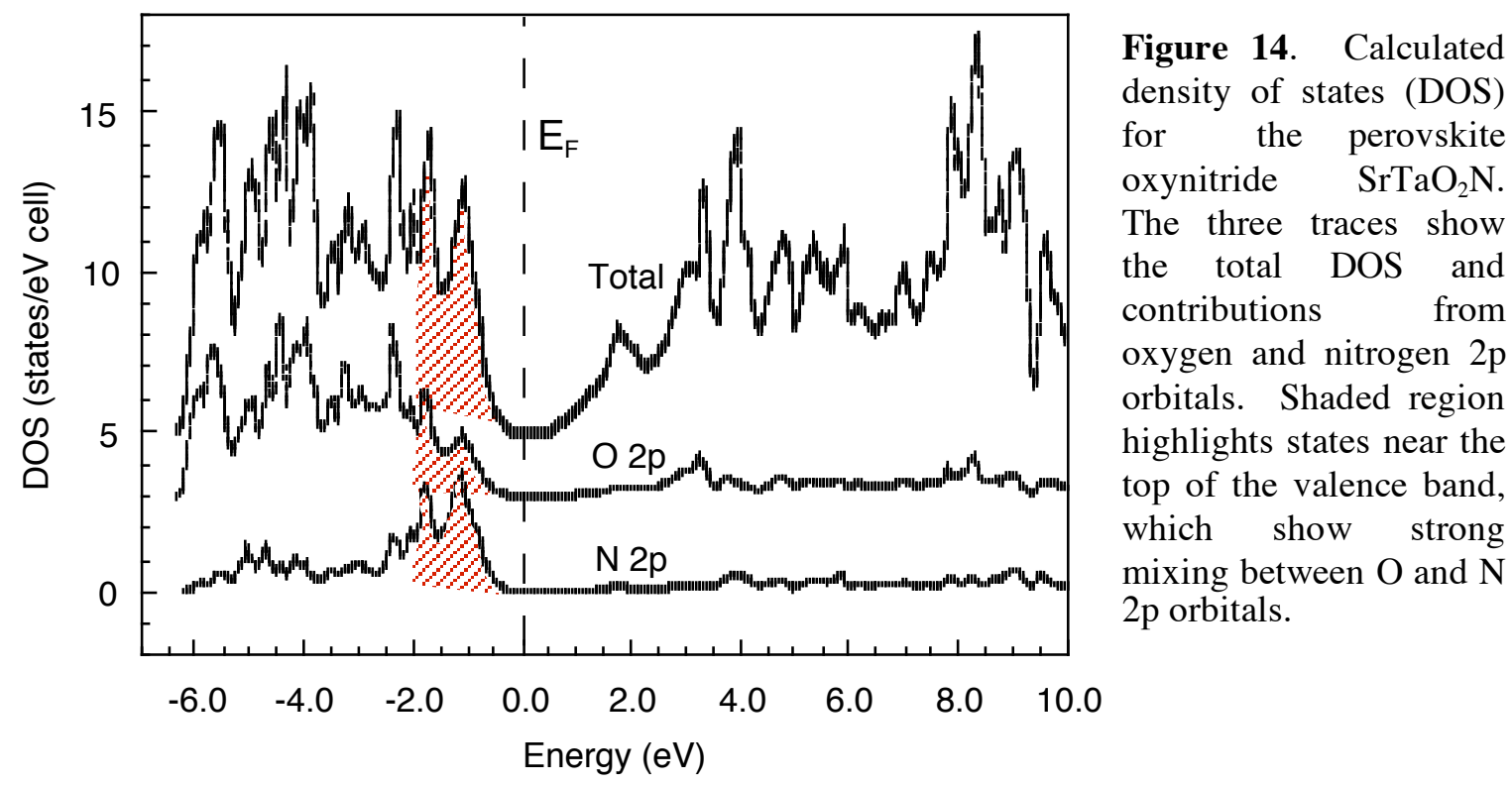


Interestingly, there is substantial mixing of $\mathrm{N} 2 \mathrm{p}$ and $\mathrm{O} 2 \mathrm{p}$ states at the top of the band. Asahi, et al., attributed the photocatalytic activity of $\mathrm{TiO}_{2-\mathrm{x}} \mathrm{N}_{\mathrm{x}}$ to the fact that mixing of this type imparts mobility to $\mathrm{N} 2 \mathrm{p}$ hole states. ${ }^{35}$

We also synthesized and studied the layer perovskite oxynitrides $\mathrm{Rb}_{1.8} \mathrm{Ca}_{2} \mathrm{Nb}_{3} \mathrm{O}_{9.2} \mathrm{~N}_{0.8} 0.6 \mathrm{H}_{2} \mathrm{O}$, and $\mathrm{Rb}_{1.7} \mathrm{LaNb}_{2} \mathrm{O}_{6.3} \mathrm{~N}_{0.7} 0.6 \mathrm{H}_{2} \mathrm{O}$, which are visible-light absorbing structural analogues of the known $\mathrm{UV}$ photocatalyst $\mathrm{RbCa}_{2} \mathrm{Nb}_{3} \mathrm{O}_{10}$. Threedimensional perovskite oxynitrides, such as $\mathrm{LaTiO}_{2} \mathrm{~N}$, are known to evolve $\mathrm{H}_{2}$ and $\mathrm{O}_{2}$ from solutions containing sacrificial donors $(\mathrm{MeOH})$ and acceptors $\left(\mathrm{Ag}^{+}\right)$, respectively. A lamellar oxynitride would in principle allow us to incorporate colloidal catalysts by intercalation as we have done with $\mathrm{RbCa}_{2} \mathrm{Nb}_{3} \mathrm{O}_{10}$ and related materials. Unfortunately, the layered oxynitrides are too unstable in aqueous solutions to be useful photocatalysts. ${ }^{67}$

b. Semiconductor Nanowires. Another idea that we are exploring is the photoelectrochemistry of semiconductor nanowires. We hope to achieve single crystal-like efficiency with array photoelectrodes, and to make in-wire junctions to drive photochemical water splitting. These arrays in principle separate the length scales of light absorption (which occurs along the axis of the wire) and charge separation (transverse to the wire), opening interesting new possibilities for photoelectrochemistry.

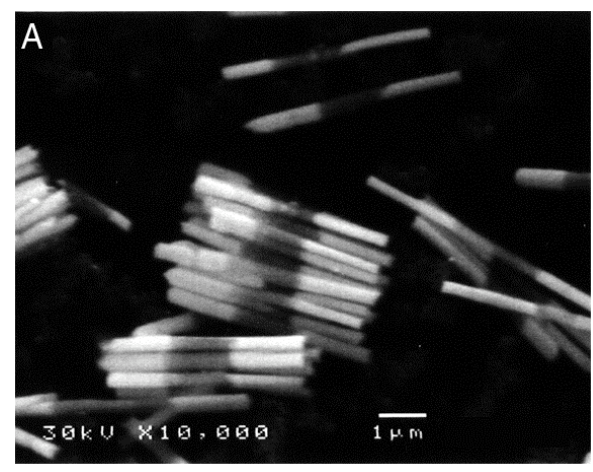

Figure 15. SEM images of $350 \mathrm{~nm}$ diameter Au-CdSe$\mathrm{Au}$ nanowires (A), and a $70 \mathrm{~nm}$ diameter $\mathrm{Ni}-\mathrm{CdSe}-\mathrm{Ni}$ nanowire (B) grown in anodic alumina templates. The lower panel in (B) shows a higher magnification TEM image of a $70 \mathrm{~nm}$ diameter CdSe segment.

We have made arrays of metal-CdSe-metal wires in the 70 and $350 \mathrm{~nm}$ diameter pores of commercial alumina membranes by room temperature electrodeposition. While these

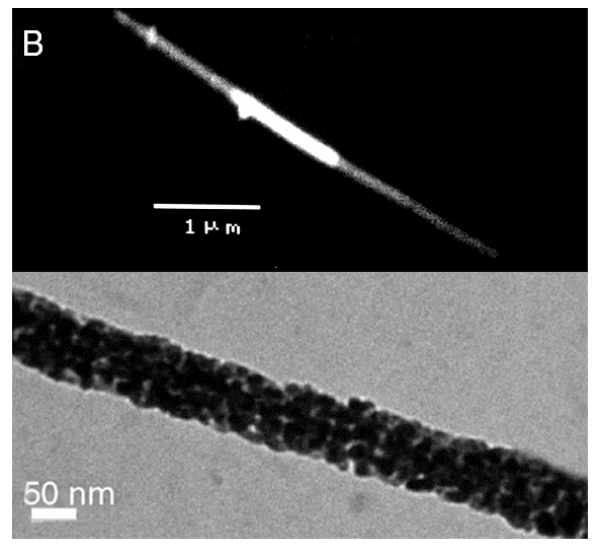
semiconductor nanowires are polycrystalline (see Fig. 15) and therefore unlikely to be good photoelectrodes, they can be used as seed layers for vapor growth of more perfect crystals. We have verified that electrochemically grown $\mathrm{CdSe}$ nanowires make rectifying contacts to $\mathrm{Au}$ and $\mathrm{Ni}$ end caps, and that the semiconducting segments of these wires are good photoconductors. ${ }^{68}$

We have also grown arrays of high quality n$\mathrm{CdSe}, \mathrm{p}-\mathrm{Si}$, and $\mathrm{n}-\mathrm{Si}$ single crystal nanowires in AAO by vapor-liquid-solid (VLS) methods. The CdSe nanowires have low levels of extrinsic doping and are good candidates for fabrication of liquid junction and conducting polymer Schottky barrier photocells. Fabrication of these cells is currently in progress. Control of the adventitious of $\mathrm{p}$ - and $\mathrm{n}-\mathrm{Si}$ nanowires has been more problematic; however, doping levels as low as $10^{17} / \mathrm{cc}$ have been achieved in p-type wires, and the hole mobility has been measured in individual wires. We are now working to control the surface chemistry of the Si nanowires and to fabricate and characterize p-Si liquid junction cells. 


\section{References}

1 (a) Faulkner, L. R.; Suib, S. L.; Renschler, C. L.; Green, J. M.; Bross, P. R. in Chemistry in Energy Production, R. G. Wymer and O. L. Keller, Eds., John Wiley and Sons (New York), 1982, pp. 99-114; (b) Krueger, J. S.; Mallouk, T. E. "Redox Catalysis and Photochemistry in Zeolites," in Kinetics and Catalysis in Microheterogeneous Media, M. Grätzel and K. Kalyanasundaram, Eds., Marcel Dekker, New York, 1991, pp. 461-490; (b) Bard, A. J.; Mallouk, T. E. "Electrodes Modified with Clays, Zeolites, and Related Microporous Solids," in Molecular Design of Electrode Surfaces, R. W. Murray, Ed., Wiley, New York, 1992, pp. 271312.

2 (a) De Wilde, W.; Peeters, G.; Lunsford, J. H. J. Phys. Chem. 1980, 84, 2306; (b) Dutta, P. K.; Incavo, J. A. J. Phys. Chem. 1987, 91, 4443; (c) Incavo, J. A.; Dutta, P. K. J. Phys. Chem. 1990, 94, 3075; (d) Dutta, P. K.; Turbeville, W. J. Phys. Chem. 1992, 96, 5024; (e) Dutta, P. K.; Turbeville, W. J. Phys. Chem. 1992, 96, 9410; (f) Borja, M; Dutta, P. K. Nature 1993, 362, 43; (g) Maruszewski, K; Strommen, D. P.; Kincaid, J. R. J. Am. Chem. Soc. 1993, 115, 8345.

3 (a) Blattter, F.; Frei, H. J. Am. Chem. Soc. 1993, 115, 7501; (b) Blatter, F.; Frei, H. J. Am. Chem. Soc. 1994, 116, 1812; (c) Blatter, F.; Moreau, F.; Frei, H. J. Phys. Chem. 1994, 98, 13403; (d) Sun, H.; Blatter, F.; Frei, H. J. Am. Chem. Soc. 1994, 116,7951 .

4 (a) Krueger, J. S.; Mayer, J. E.; Mallouk, T. E. J. Am. Chem. Soc. 1988, 110, 8232;

(b) Yonemoto, E. H.; Kim, Y. I.; Schmehl, R. H.; Wallin, J. O.; Shoulders, B. A.; Richardson, B. R.; Haw, J. F.; Mallouk, T. E., J. Am. Chem. Soc. 1994, 116, 10557.

5 Brigham, E. S.; Snowden, P. T.; Kim, Y. I.; Mallouk, T. E. J. Phys. Chem. 1993, 97, 8650 .

6 Yonemoto, E. H.; Schmehl, R. H.; Hubig, S. M.; Riley, R. L.; Iverson, B. L.; Mallouk, T. E. J. Am. Chem. Soc. 1994, 116, 4786.

7 (a) Cao, G.; Hong, H.-G.; Mallouk, T. E. Acc. Chem. Res. 1992, 25, 420; (b) Mallouk, T. E.; Kim, H.-N.; Ollivier, P. J.; Keller, S. W. "Ultrathin Films Based on Layered Materials", Comprehensive Supramolecular Chemistry, G. Alberti and T. Bein, Eds., Elsevier Science, Oxford, UK, 1996, pp. 189-218.

8 (a) Kleinfeld, E.R.; Ferguson, G.S. Science 1994, 265, 370; (b) Keller, S.W.; Kim, H.-N.; Mallouk, T.E. J. Am. Chem. Soc. 1994, 116, 8817.

9 Kressin, A. M.; Doan, V. V.; Klein, J. D.; Sailor, M. J. Chem. Mater. 1991, 3, 10151020 .

10 Klein, J. D.; Herrick, R. D.; Palmer, D.; Sailor, M. J.; Brumlik, C. J.; Martin, C. R. Chem. Mater. 1993, 5, 902-904. 
11 (a) Yu, J.-Y.; Chung, S.-W.; Heath, J. R., J. Phys. Chem. B 2000, 104, 11864; (b) Huang, Y.; Duan, X.; Wei, Q.; Lieber, C. M. Science 2001, 291, 630.

12 Gundiksen, M. S.; Lieber, C. M., J. Am. Chem. Soc. 2000, 122, 8801.

13 Gundiksen, M.; Lauhon, L. J.; Wang, J.; Smith, D. C.; Lieber, C. M., Nature 2002, $415,617$.

14 Wu, Y.; Fan, R.; Yang, P. Nano Lett. 2002, 2, 83.

15 Haraguchi, K.; Katsuyama, T.; Hiruma, K., J. Appl. Phys. 1994, 75, 4220.

16 Markowitz, P. D.; Zach, M. P.; Gibbons, P. C.; Penner, R. M.; Buhro, W. E. J. Am. Chem. Soc. 2001, 123, 4502.

17 Bjork, M. T.; Ohlsson, B. J.; Sass, T.; Persson, A. I.; Thelander, C.; Magnusson, M. H.; Deppert, K.; Wallenberg, L. R.; Samuelson, L. Nano Lett. 2002, 2, 87.

18 Gates, B.; Wu, Y.; Yang, P.; Xiao, Y., J. Am. Chem. Soc. 2001, 123, 11500.

19 Zhang, X. Y.; Zhang, L. D.; Chen, W.; Meng, G. W.; Zheng, M. J.; Zhao, L. X., Chem. Mater. 2001, 13, 2511.

20 Kind, H.; Yan, H.; Messer, B.; Law, M.; Yang, P., Adv. Mater. 2002, 14, 158.

21 Schaak, R. E.; Mallouk, T. E., Chem. Mater. 2002, 14, 1455-1471.

22 Keller, S. W.; Johnson, S. A.; Brigham, E. S.; Yonemoto, E. H.; Mallouk, T. E. J. Am. Chem. Soc. 1995, 117, 12879.

23 Kaschak, D. M.; Johnson, S. A.; Waraksa, C. C.; Pogue, J.; Mallouk, T. E. Coord. Chem. Rev. 1999, 186, 403.

24 Kaschak, D. M.; Lean, J. T.; Waraksa, C. C.; Saupe, G. B.; Usami, H.; Mallouk, T. E. J. Am. Chem. Soc. 1999, 121, 3435.

25 Kaschak, D. M.; Johnson, S. A.; Hooks, D.; Kim, H.-N.; Ward, M. D.; Mallouk, T. E. J. Am. Chem. Soc. 1998, 120, 10887.

26 (a) Alberti, G. Acc. Chem. Res. 1978, 11, 163; (b) Clearfield, A. Chem. Rev. 1988, $88,125$.

27 M. Suzuki, C. C. Waraksa, T. E. Mallouk, H. Nakayama, and K.Hanabusa, "Enhanced Photocatalytic Reduction of Methylviologen by Self-Assembling Ruthenium(II)Poly(pyridyl) Complexes with L-Lysine Containing Side Chains," J. Phys. Chem. B, 106, 4227-4231 (2002). 
28 M. Suzuki and T. E. Mallouk, "Photosensitized Production of Doubly Reduced Methylviologen Followed by Highly Efficient Methylviologen Radical Formation using Self-Assembling Ruthenium(II) Complexes," J. Chem. Soc., Chem. Comm., 1534-1535 (2002).

29 Kim, Y. I.; Salim, S.; Huq, M. J.; Mallouk, T. E. J. Am. Chem. Soc. 1991, 113, 9561.

30 Kim, Y. I.; Atherton, S. J.; Brigham, E. S.; Mallouk, T. E. J. Phys. Chem. 1993, 97, 11802.

31 Grätzel, M., Nature 2001, 414, 338.

32 Kamat, P. V. Chem. Rev. 1993, 93, 267.

33 Saupe, G. B.; Mallouk, T. E.; Kim, W.; Schmehl, R. H. J. Phys. Chem. B 1997, 101, 2508 .

34 Domen, K.; Yoshimura, J.; Sekine, T.; Tanaka, A.; Onishi, T. Catal. Lett. 1990, 4, 339.

35 Morrison, S. R. Electrochemistry at Semiconductor and Oxidized Metal Electrodes; Plenum Press: New York, 1980.

36 Sanderson, R. T. Chemical Periodicity; Reinhold: New York, 1960.

37 Butler, M. A.; Ginley, D.S. J. Electrochem. Soc. 1978, 125, 228.

38 Kim, Y. I.; Keller, S. W.; Krueger, J. S.; Yonemoto, E. H.; Saupe, G. B.; Mallouk, T. E. J. Phys. Chem. B 1997, 101, 2491.

39 Kinomura, N.; Kumada, N.; Muto, F. J. Chem. Soc., Dalton Trans. 1985, 2349.

40 Saupe, G. B.; Mallouk, T. E.; Kim, W.; Schmehl, R. H. J. Phys. Chem. B 1997, 101, 2508.

41 G. B. Saupe, C. C. Waraksa, H.-N. Kim, Y. J. Han, D. M. Kaschak, D. M. Skinner, and T. E. Mallouk, Chem. Mater., 12, 1556-1562 (2000).

42 Naruta, Y.; Sasayama, M.; Sasaki, T. Angew. Chem., Int. Ed. 1994, 33, 1839.

43 (a) Hammarstrom, L.; Sun, L.; Akermark, B.; Styring, S. Catal. Today 2000, 58, 57-69; (b) Sun, L.; Hammarstrom, L.; Akermark, B.; Styring, S. Chem. Soc. Rev. 2001, 30, 36-49.

44 Khairutdinov, R. F.; Hurst, J. K. Nature 1999, 402, 509-511. 
45 Limburg, J.; Vrettos, J.S.; Liable-Sands, L.M.; Rheingold, A.L.; Crabtree, R.H.; Brudvig, G.W. Science 1999, 283, 1524.

46 Limburg, J.; Vrettos, J.S.; Chen, H.; de Paula, J.C.; Crabtree, R.H.; Brudvig, G.W. J. Am. Chem. Soc. 2001, 123, 423.

47 Yamada, H.; Siems, W.F.; Koike, T.; Hurst, J.K. J. Am. Chem. Soc. 2004, 126, 9786.

48 Hurst, J.K. Coord. Chem. Rev., 2005, 249, 313-328.

49 Ruettinger, W.; Dismukes, C. G. Chem. Rev. 1997, 97, 1.

50 Kiwi, J.; Gratzel, M. Nature 1979, 285, 657.

51 Kiwi, J.; Gratzel, M. J. Am. Chem. Soc. 1979, 101, 7214.

52 Harriman, A.; Thomas, J.M.; Millward, G.R. New J. Chem. 1987, 11, 757.

53 Harriman, A.; Pickering, I.J.; Thomas, J.M.; Christensen, P.A. J. Chem. Soc., Faraday Trans. I 1988, 84, 2795.

54 Hara, M.; Waraksa, C. C.; Lean, J. T.; Lewis, B. A.; Mallouk, T. E. J. Phys. Chem. A 2000, 104, 5275.

55 Harriman, A.; Richoux, M.; Christensen, P.A.; Moseri, S.; Neta, P. J.Chem. Soc., Faraday Trans. I 1987, 83, 3001.

56 Ghosh, P. K.; Brunschwig, B.S.; Chou, M.; Creutz, C.; Sutin, N. J. Am. Chem. Soc. 1984, 106, 4772.

57 Harriman, A.; Pickering, I.J.; Thomas, J.M.; Christensen, P.A. J. Chem. Soc., Faraday Trans. I 1988, 84, 2795.

58 Hara, M.; Waraksa, C. C.; Lean, J. T.; Lewis, B. A.; Mallouk, T. E. J. Phys. Chem. A 2000, 104, 5275.

59 Nahor, G. S.; Hapiot, P.; Neta, P.; Harriman, A. J. Phys. Chem. 1991, 95, 616.

60 Hara, M.; Mallouk, T. E. Chem. Comm. 2000, 1903.

61 Hara, M.; Lean, J. T.; Mallouk, T. E. Chem. Mater. 2001, 13, 4668.

62 Morris, N. D.; Mallouk, T. E. J. Am. Chem. Soc. 2002, 124, 11114-11121.

63 Morris, N. D.; Suzuki, M.; Mallouk, T. E. J. Phys. Chem. A 2004, 108, 9115. 
64 Nahor, G. S.; Hapiot, P.; Neta, P.; Harriman, A. J. Phys. Chem. 1991, 95, 616.

65 Self-consistent band structure calculations were performed within the local density approximation (LDA). The one-electron solutions to the Schrödinger equation employed the linear muffin tin orbital (LMTO) method in the atomic spheres approximation (ASA). These calculations underestimate the band gap of $\mathrm{KTaO}_{3}$ (and also $\mathrm{SrTiO}_{3}$ ) but give useful insight into trends in band gaps and $\mathrm{N}-\mathrm{O}$ orbital mixing for the analogous oxynitrides. For details of the method see (a) O. K. Andersen and O. Jepsen, Phys. Rev. Lett. 1984, 53, 2571; (b) O. K. Andersen, Z. Pawlowska, and O. Jepsen, Phys. Rev. B 1986, 34, 5253.

66 Günther, E.; Hagenmayer, R.; Jansen, M. Z., Z. Anorg. Allgem. Chem. 2000, 626, 1519.

67 J. A. Schottenfeld, G. Chen, P. C. Ekerdt, and T. E. Mallouk, "Synthesis and Characterization of Layered Perovskite Oxynitride Photocatalysts from DionJacobson Oxide Precursors," J. Solid State Chem. 178, 2313-2321 (2005).

68 D. J. Peña, J. K. N. Mbindyo, A. J. Carado, T. E. Mallouk, C. D. Keating, B. Razavi, and T. S. Mayer, "Template Growth of Photoconductive Metal-CdSe-Metal Nanowires," J. Phys. Chem. B, 106, 7458-7462 (2002). 